\title{
An ecotoxicological view on neurotoxicity assessment
}

\author{
J. B. Legradi ${ }^{1} 2^{*}$, C. Di Paolo ${ }^{1}$, M. H. S. Kraak³, H. G. van der Geest ${ }^{3}$, E. L. Schymanski ${ }^{4}$, A. J. Williams ${ }^{5}$, \\ M. M. L. Dingemans ${ }^{6}$, R. Massei ${ }^{7}$, W. Brack ${ }^{7}$, X. Cousin ${ }^{8,9}$, M.-L. Begout ${ }^{10}$, R. van der Oost ${ }^{11}$, A. Carion ${ }^{12}$, \\ V. Suarez-Ulloa ${ }^{12}$, F. Silvestre ${ }^{12}$, B. I. Escher ${ }^{13,14}$, M. Engwall ${ }^{15}$, G. Nilén ${ }^{15}$, S. H. Keiter ${ }^{15}$, D. Pollet ${ }^{16}$, P. Waldmann ${ }^{16}$, \\ C. Kienle ${ }^{17}$, I. Werner ${ }^{17}$, A.-C. Haigis ${ }^{1}$, D. Knapen ${ }^{18}$, L. Vergauwen ${ }^{18}$, M. Spehr ${ }^{19}$, W. Schulz ${ }^{20}$, W. Busch ${ }^{21}$, \\ D. Leuthold ${ }^{21}$, S. Scholz ${ }^{21}$, C. M. vom Berg ${ }^{22}$, N. Basu ${ }^{23}$, C. A. Murphy ${ }^{24}$, A. Lampert ${ }^{25}$, J. Kuckelkorn²6, \\ T. Grummt ${ }^{26}$ and H. Hollert ${ }^{1 *}$
}

\begin{abstract}
The numbers of potential neurotoxicants in the environment are raising and pose a great risk for humans and the environment. Currently neurotoxicity assessment is mostly performed to predict and prevent harm to human populations. Despite all the efforts invested in the last years in developing novel in vitro or in silico test systems, in vivo tests with rodents are still the only accepted test for neurotoxicity risk assessment in Europe. Despite an increasing number of reports of species showing altered behaviour, neurotoxicity assessment for species in the environment is not required and therefore mostly not performed. Considering the increasing numbers of environmental contaminants with potential neurotoxic potential, eco-neurotoxicity should be also considered in risk assessment. In order to do so novel test systems are needed that can cope with species differences within ecosystems. In the field, online-biomonitoring systems using behavioural information could be used to detect neurotoxic effects and effect-directed analyses could be applied to identify the neurotoxicants causing the effect. Additionally, toxic pressure calculations in combination with mixture modelling could use environmental chemical monitoring data to predict adverse effects and prioritize pollutants for laboratory testing. Cheminformatics based on computational toxicological data from in vitro and in vivo studies could help to identify potential neurotoxicants. An array of in vitro assays covering different modes of action could be applied to screen compounds for neurotoxicity. The selection of in vitro assays could be guided by AOPs relevant for eco-neurotoxicity. In order to be able to perform risk assessment for eco-neurotoxicity, methods need to focus on the most sensitive species in an ecosystem. A test battery using species from different trophic levels might be the best approach. To implement eco-neurotoxicity assessment into European risk assessment, cheminformatics and in vitro screening tests could be used as first approach to identify eco-neurotoxic pollutants. In a second step, a small species test battery could be applied to assess the risks of ecosystems.
\end{abstract}

Keywords: Eco-neurotoxicity, Neurotoxicity, EDA, REACH, AOP, Behaviour, Computational toxicity, Ecological, Species

\footnotetext{
*Correspondence: jessica.legradi@bio5.rwth-aachen.de; henner. hollert@bio5.rwth-aachen.de

${ }^{1}$ Institute for Environmental Research, Department of Ecosystem Analysis,

ABBt-Aachen Biology and Biotechnology, RWTH Aachen University,

Worringerweg 1, 52074 Aachen, Germany

Full list of author information is available at the end of the article
} 


\section{Background}

Neurotoxic pollutants are an emerging issue beyond human health because neurotoxicants causes potentially serious threats to vertebrate and invertebrate populations and ecosystems in general. Indeed, neurotoxic chemicals are suspected to produce changes in organism behaviour (e.g. mating behaviour, predator escape response and feeding behaviour), which can reduce an individual's fitness, lead to population declines and ultimately have severe impacts on ecosystems [1]. Different classes of environmental contaminants, including metals and organic pollutants, were shown to affect the performance of complex behaviours in different fish species [2] and in wildlife [3, 4]. In wildlife, as in humans, early life stages are particularly sensitive to toxicant insults. Additionally, neurotoxic effects in early life stages might not be directly visible but lead to detrimental effects later in life. Besides, exposure to neurotoxic compounds can trigger epigenetic pathways which can underlie long-term effects as well as multior transgenerational effects $[5,6]$.

Typically, several thousand compounds are detectable in environmental samples, including synthetic and natural compounds and their transformation products [7]. However, knowledge regarding the neurotoxic potential of environmental contaminants in ecosystems is very limited, since the assessment of neurotoxicity is currently mostly focused on human exposure to individual chemicals. Known human neurotoxic or neuroactive compounds, such as pesticides, pharmaceuticals, and heavy metals, occur in the environment together with thousands of chemicals with unknown neurotoxic potential to different species and life stages. It has been estimated that up to $30 \%$ of all commercially used chemicals $(\sim 30,000$ chemicals $)$ may have neurotoxic potential [8]. Additionally, in a recent literature study looking at the known modes of action (MoA) of organic contaminants detected in freshwater monitoring studies, neurotoxicity was identified as the MoA linked to nearly $30 \%$ of all detected chemicals [9]. This shows the relevance of detecting neurotoxic compounds in the environment, increasing the demand for bioanalytical tools capable of identifying and possibly quantifying neurotoxic effects in organisms inhabiting contaminated ecosystems.

The aim of this article is to provide a critical overview of the state of the art of hazard characterization, effects, bioassays and chemical approaches regarding neurotoxicity in organisms as well as for ecosystems. This review will contribute a scientific perspective on the needs and future directions in neurotoxicity assessment for environmental protection (cf. Fig. 1).

\section{Environmental neurotoxicity versus eco-neurotoxicity}

Neurotoxicity can be defined as the capacity of agents (chemical, biological, or physical) to cause adverse functional or structural changes in the nervous system [10]. Environmental neurotoxicity describes neurotoxicity caused by exposure to chemicals in the environment and commonly refers to human exposure and human neurotoxicity [10]. In contrast, we define ecological neurotoxicity (eco-neurotoxicity) as neurotoxicity resulting from exposure to environmental chemicals in species other than humans (e.g. fish, birds, invertebrates). It is important to distinguish between human and non-human neurotoxicity as the effects of exposure to compounds, both in terms of levels and pathways, as well as the structure and function of the nervous system itself, can differ widely between species.

\section{Current role of eco-neurotoxicology in risk assessment for regulation \\ REACH/EU general food law}

Within the current European chemical regulation, neurotoxicity is only assessed using in vivo test systems [11]. The EU legislation for industrial chemicals (REACH) assesses neurotoxicity only for compounds produced $\geq 10$ tons/year. These compounds need to be tested with standard oral 28-day and 90-day toxicity studies in rodents. Clinical observations including motor activity, a functional observational battery and histopathological assessments of the spinal cord and sciatic nerve can be indicators of neurotoxicity. If these tests indicate neurotoxicity at levels below systemic toxicity, more detailed neurotoxicity tests are required (OECD technical guideline (TG) 424 to assess neurotoxicity and TG 426 to assess developmental neurotoxicity).

In terms of ecotoxicological impacts, current guidelines for neurotoxicity assessment in vertebrates focus on mammals and birds [12-16]. There is no regulatory guideline available to identify neurotoxic risks to other vertebrates or invertebrate animals. Furthermore, thus far there is no European regulatory framework for econeurotoxicity assessment.

Within risk assessment and risk management of econeurotoxic substances, pesticides are a substance class of special interest. Some pesticides kill pests via neurotoxic mechanisms. Neurotoxic actions on non-target species have been determined for several species and pesticides [17-22]. The European Food Safety Agency (EFSA) is responsible for the registration of pesticides and all other substances that can contact or occur in food and are not assessed under REACH. Until now, the active compounds in pesticides need to be assessed for potential 
neurotoxic effects in mammals using the same rodent studies as under REACH (TG 424 and TG 426) only if it is indicative from their intended MoA or other information, like chemical structure, that the substance could be neurotoxic [23]. Neurotoxic effects on non-target species in the environment are not assessed.

\section{Water Framework Directive}

The European Water Framework Directive (WFD) aims to integrate biological and chemical information to obtain an overall insight into the quality of individual water bodies. According to the WFD, the chemical status of a water body is determined by analysing the concentrations of 45 priority substances, which are not selected based on their potential neurotoxicity. A good chemical status is defined by concentrations of all of these substances below the annual average and maximum allowable Environmental Quality Standards (AA- and MAC-EQSs), which are defined to protect the environment and human health [24].

As a result, regular chemical monitoring of the water quality is almost exclusively performed by targeted chemical analysis of a limited set of (indicator) compounds. There are, however, some serious limitations related to the use of target chemical analyses of large volume samples for monitoring the overall chemical status of a water body. First, because only a limited number of target substances are analysed, the risk of other, nonpriority and unknown substances in the aquatic environment remains unknown [25]. At present (August 2018), more than $142,000,000$ substances are registered in SciFinder with the Chemical Abstracts Service, while there are over 140,000 substances that are produced over 1 ton/year listed in REACH. Some of those compounds might eventually end up in the environment. Second, it is obvious that chemicals do not occur alone in the environment, but as complex mixtures. While concentrations of individual chemicals can be below the lowest observed effect concentrations (LOEC) or detection limits, the entire mixture may still cause adverse effects [26]. Moreover, transformation products of micropollutants formed in the environment or by biological metabolism are not always known or registered and may be more toxic and persistent than the parent compounds [27]. These limitations may thus result in an incomplete assessment of chemical hazards and risks, e.g. [28], urging alternative approaches to be explored [29].

\section{German drinking water ordinance}

There is an urgent need for quick assessments of substances with unknown toxicological potential to prevent possible harm for consumers by water suppliers and public health departments, who supervise the process. At this time, there is no explicit regulation for neurotoxicity in drinking water in countries like Germany. While the German Drinking Water Ordinance (TrinkwV 2018) [30] gives threshold values for some metals, e.g. lead, cadmium, arsenic, with a known neurotoxic potential [31], no specific endpoints or proposals for a testing strategy are given for neurotoxicity.

The health-related indicator value (HRIV; in German: Gesundheitsbasierter Orientierungswert, GOW) concept provides a temporary value for toxicologically unknown single substances detected in drinking water systems. This hierarchically built concept is based on a precautionary in vitro approach with endpoints related to genotoxicity, neurotoxicity, endocrine disrupting effects and (sub-)chronic effects [32]. In a first step, several cell-based assays are used to detect effects of water concentrates or individual chemicals on basic parameters like apoptosis, necrosis and oxidative stress in HepG2 liver cells, Jurkat and U-937 blood cells. In a second step, organ-specific effects are compared between SH-SY5Y nerve cells and HepG2 liver cells using RTCA $^{\mathrm{TM}}$ and Caspase assay. Finally, neurotoxic effects like neural differentiation of SH SY5Y cells are measured. Therefore, this concept can be used for high-throughput screening with the first and second test level and for determining neurotoxicity-effect concentrations in the third assay step. Furthermore, this approach can be applied to compare chemicals or exposure situations, although other neurotoxic mechanisms may remain obscured. The current approach could be extended also for eco-neurotoxicity assessment.

\section{Developmental eco-neurotoxicity}

Developmental neurotoxicity (DNT) is particularly concerned with the effects of toxicants on the developing nervous system of organisms. The developing brain and nervous system is supposed to be more sensitive to toxic effects than the mature brain and nervous system [33]. Such studies must consider the temporal and regional occurrence of critical developmental processes of the nervous system, and the fact that early life exposure can lead to long-lasting or delayed neurotoxic effects [33].

Despite particular concern, the availability of information regarding developmental neurotoxicity of chemicals is very limited, even for humans. In a systematic literature review considering the neurotoxic potential of industrial chemicals to human populations, Grandjean and Landrigan identified 201 proven human neurotoxicants [34] and, moreover, they estimate that there are over 1000 compounds which were neurotoxic in laboratory animals, respectively [21]. Five of the 201 chemicals identified as human neurotoxicants were also classified as developmental neurotoxicants, while the other compounds could 
not be classified due to lack of experimental data [34]. Such low numbers demonstrate a clear lack of developmental neurotoxicity assessment studies. Additionally, a 2009 report indicated that only around 110 chemicals had been tested for potential human developmental neurotoxicity following respective OECD or US-EPA guidelines [35, 36]. As a consequence, there is a demand for time and cost-efficient testing methods capable of evaluating large numbers of chemicals for developmental neurotoxicity. Such methods may include in vitro and in silico tools as well as in vivo studies with alternative model species such as zebrafish (Danio rerio) [36]. Based on the 2009 reports $[35,36]$, an international collaboration was started led by Prof. E. Fritsche (IUF) with the goal to assemble a developmental neurotoxicity (DNT) testing battery for regulatory purposes. The in vitro testing battery will cover a variety of neurodevelopmental key events, distinct brain cell types and will investigate over 100 potential developmental neurotoxicants [37].

Developmental eco-neurotoxicity not only has to deal with similar challenges as for human neurotoxic investigations, such as complex temporal toxicity profiles due to different sensitivities of developmental stages combined with diverse target site susceptibility due to the complexity of the nervous system (depending on the species of interest), but in addition must consider the ecotoxicological perspective [38]. As a result, eco-neurotoxicity studies must aim to focus on protecting the most sensitive organisms and respective developmental stages among the multitude of different species in the environment.

In this sense, it is of great advantage that developmental eco-neurotoxicity can benefit from the knowledge obtained with model organisms such as the fish species medaka and zebrafish. Such fish models are used in both (developmental) neurotoxicity as well as in ecotoxicological studies, with investigations considering the involved MoAs and mechanisms of toxicity. For instance, changes in protein expression and whole mount antibody staining in medaka early life stages have been proposed as methodological approaches to characterize neurotoxic effects and respective mechanisms involved [39]. Zebrafish early life stages have been used as model organisms in a screening protocol to investigate environmental neurotoxicants considering various nervous system endpoints [40] and were proposed as systems toxicology models to support the identification of pathways of developmental neurotoxicity [41]. There are similar approaches with invertebrates, for example the characterization of sea urchins, which use neurotransmitters as embryonic growth regulatory signals, as model organisms for developmental neurotoxicity testing [42, 43]. Behavioural screening systems developed for zebrafish have also been applied for invertebrates like flat- and roundworms [44].
The nematode, Caenorhabditis elegans, is already a commonly used model organism for developmental biology and recently emerged as model organism for human neurotoxicity studies [45]. Their size makes them ideally suited for high-throughput behavioural screening approaches, whereas their well-known neurophysiology can be used to identify and study neurotoxic mechanisms. Although mostly used for human studies so far, flat- and roundworms could be easily used for environmental studies. There is also growing interest in using avian models, particularly the use of in ovo egg injection methods in which developmental exposures can be carefully controlled and linked with a range of structural and functional outcomes in the hatchling and later life stages $[46,47]$.

In the long run, developmental eco-neurotoxicity should integrate the outcomes of experimental investigations utilizing such ecotoxicologically relevant organisms with data from in vitro and in silico predictive models, in a similar way as proposed for humans [37]. In order to be successful, predictive developmental eco-neurotoxicity should consider the diverse mechanisms and MoAs involved, as well as their variation across species and toxicants, as already suggested for predictive ecotoxicology in support of ecological risk assessment [48, 49].

\section{Epigenetics in eco-neurotoxicity}

Epigenetics can be defined as the study of changes in gene expression that occur without changes in the DNA sequence, and which may be heritable. Inheritance is understood in two different ways; mitotic inheritance (i.e. from cell-to-cell through cell division) and meiotic inheritance (i.e. from one organism to its offspring through reproduction) [50]. Three main epigenetic mechanisms are generally described: DNA methylation, histone modifications and non-coding RNA [51, 52]. Cell-to-cell inheritance involves the maintenance of epigenetic marks during the life of the individual, offering very interesting hypotheses for delayed effects of exposure to toxicants in early stages of life. On the other hand, transgenerational inheritance of epigenetic marks could explain how specific traits that were induced by exposure to toxicants can be observed in offspring that itself is not directly exposed [53].

DNA methylation is the most studied epigenetic modification and consists in the methylation of cytosine nucleotides in the genome by DNA methyltransferase (DNMTs). One particularity of DNA methylation is that it can be depleted and replaced again during epigenetic reprogramming events to set up cell- and tissue-specific gene expression $[52,54]$. More precisely, DNA methylation patterns are reprogrammed across the whole genome in early embryos and primordial germ cells. This 
is well known in the case of mammals $[55,56]$, but it has also been observed in flowering plants and other animals such as fish [57-59]. This process is essential for a normal development of the animal brain as it modulates the expression of neural genes during specific developmental time periods, but it may also represent a particularly vulnerable period for an exposure to toxicants $[60,61]$. Consequently, an early life stage exposure to neurotoxicants may thus impact the later or adult phenotype by interfering with reprogramming, leading to negative consequences on the development of the central nervous system (CNS) [6, 62].

The exact MoAs of neurotoxic compounds on the epigenome are almost completely unknown. Neurotoxic effects of pollutants can be channelled by oxidative stress, mainly interfering with the ability of DNMTs to link and interact with DNA [5, 6]. Similarly, transient exposure to chemical compounds such as bisphenol A or valproic acid in the womb can alter DNA methylation and histone deacetylation processes, which has been linked to persistent consequences such as defective brain development and memory loss in later stages of life [63]. Parallel work in metals demonstrates that epigenetics may be a critical pathway for metal-induced neurotoxicity as a result of $\mathrm{Fe}$, As or Cd exposure [6]. Impairment of human and animal behaviour following either pre- or post-natal exposure to neurotoxicants has been recorded and linked with neurodegenerative diseases in adults [64-67]. However, the role of epigenetics in the development of these degenerative processes requires further research.

Beyond the organism's lifetime, transgenerational epigenetic inheritance (TEI) may have critical implications for populations and species. The evaluation of a potential transmission of environmentally induced epigenetic modifications has been highlighted as a necessary field of research in ecological risk assessment [68]. Here, a clear distinction between intergenerational and transgenerational inheritance is required. The first involves a direct exposure of the germ cells that will later constitute the next generation, and the latter involves an indirect transmission of non-genetic information from one generation to another [69]. Evidence of TEI underpinning neurotoxic effects in multiple generations is very rare. A recent study by Knecht et al. reported transgenerational behavioural effects of benzo[a]pyrene on zebrafish exposed during development (hyper locomotor activity, hyper-avoidance behaviour) [70]. The same study also showed that global DNA methylation was decreased, as well as DNMT expression. Similarly, Carvan et al. showed a correlation between developmental induced transgenerational inheritance of abnormal behaviour in zebrafish exposed to methylmercury, and sperm epimutations in the second filial (F2) generation [71]. In another example, exposure of one generation of zebrafish to a complex mixture of PCBs and PBDEs simultaneously triggered changes in DNMTs expression and behaviour in larvae and/or adults in up to four non-exposed offspring generations [72].

The current understanding of epigenetics is strongly biased towards the use of laboratory animals such as mice and rats, which limits its applicability to eco-neurotoxicology. Nonetheless, the observed effects of neurotoxicity of some compounds in humans and laboratory animals can be transposed to wildlife: birds, terrestrial mammals or marine and freshwater organisms [73- 77]. For example, in a comparative study DNMT activity and DNA methylation were measured in brain tissues from methylmercury-exposed mink (mammal), chicken (bird), and yellow perch (fish), thus showcasing how relevant epigenetic measures can be incorporated into laboratory-based studies on ecologically relevant species [78]. Altered DNA methylation has also been shown in Daphnia exposed to toxicants [79], highlighting that epigenetic effects are not only occurring in vertebrates. Behaviour mediates the interaction between the organism and its environment, e.g. helping organisms adapt to new environmental conditions [80]. Appropriate behaviour is crucial for organisms to survive. Neurotoxicants in air, water and/or soil could affect the CNS and the behaviour of organisms and lead to changes in ecology, particularly if the consequences of exposure to neurotoxicants can be transmitted to following generations. Epigenetics research may hold the key to understand the mechanisms of transmission of such environmental information, potentially playing a role in processes of rapid adaptation [81]. This aspect of eco-neurotoxicity requires further investigation by the scientific community to improve the understanding of the molecular underpinnings of eco-neurotoxicity and its long-term consequences on ecosystems.

\section{Endocrine eco-neurotoxicity}

Accurate spatial and temporal hormone signalling is required for correct neuronal development. Consequently, chemicals disrupting the hormone (endocrine) signalling during neurogenesis may cause severe, irreversible cognitive defects in exposed organisms [82]. For example, perturbation of the thyroid system was associated with motor and mental disorders in rats, apes and humans and the emergence of diseases such as attentiondeficit hyperactivity disorder/syndrome [83-86]. This is of concern for regulatory authorities since endocrine active compounds are ubiquitous in the environment $[87,88]$. Hence, an increasing number of researchers are investigating the link between endocrine disruption and neurotoxicity [82, 85, 89-93]. Several studies, especially with fish, show an impact of endocrine disrupting 
chemicals (EDCs) on behaviour, which is thought to be a representative endpoint for neurotoxicity [94- 99]. Evidence also exists for quails, tadpoles and a few invertebrate species, suggesting endocrine developmental neurotoxicity after exposure to EDCs. However, further research is needed to reveal possible links [91, 100-103].

While mechanisms causing developmental neurotoxicity remain unknown [92, 104], endocrine developmental neurotoxicity is of concern for the environment since hormone systems are conserved within animal taxa [105]. Adverse effects observed in the laboratory may thus occur in wildlife [82, 87]. To avoid effects on ecosystems and perform reliable environmental risk assessment, research needs to understand the mechanisms evoking neurotoxicity [93]. In addition, mixture effects, spatial and temporal exposure scenarios and community structures need to be considered [106-108].

\section{Neurotransmitter system related modes of action of eco-neurotoxicity}

One of the MoA relevant for eco-neurotoxicity are disturbances in electric signal transduction and inhibition of chemical signal transduction, mainly through interference with the neurotransmitters [109]. Examples include the inhibition of the degradation of acetylchol ine by blocking the enzyme acethylcholinesterase (AChE) in the excitatory synapses or by inhibition of the GABA (g-aminobutyric acid) preceptor in the inhibitory synapses [110].

Environmental pollutants such as DDT bind to open sodium channels in neurons, which prevents closing of the channels and leads to over-excitation [111]. Pyrethroids, such as permethrin, increase the time of opening of the sodium channels, leading to similar symptoms [112]. Lindane and cyclodiene insecticides block GABAmediated chloride channels [113]. Organophosphate insecticides bind to $\mathrm{AChE}$ and hence prevent the degradation of acetylcholine, leading also to overexcitation and severe toxic symptoms, when over $50 \%$ of the AChE receptors are blocked. Neonicotinoids (e.g. imidacloprid) bind to the nicotinic acetylcholine receptors (nAChR), and their binding is irreversible but the potency is much higher on insect $\mathrm{nAChR}$ than on the corresponding mammalian receptors [114]. However, they are dangerous to non-target insects like bees and have been associated with a decline in the bee population [115]. Phenyl-pyrazols such as fipronil bind to GABA receptors and the selectivity for insects over mammals is also caused by a higher binding affinity [116].

Most organophosphate insecticides are thio-phosphoesters that require oxidation prior to causing inhibition of AChE as is illustrated by diazinon in Fig. 2. The oxidation catalyzed by cytochrome p450 monooxygenases transforms diazinon to diazoxon, which binds to the esterase site on the AChE by releasing the pyrimidinol species as a leaving group (in this example 2-isopropyl-6-methyl-4-pyrimidinol). The remaining AChE-phosphoester complex is then further hydrolysed, leading to a so-called ageing (irreversible binding) of the inhibitor-enzyme complex. AChE inhibitors that do not have a good secondary leaving group are reversible inhibitors as they do not age and can be

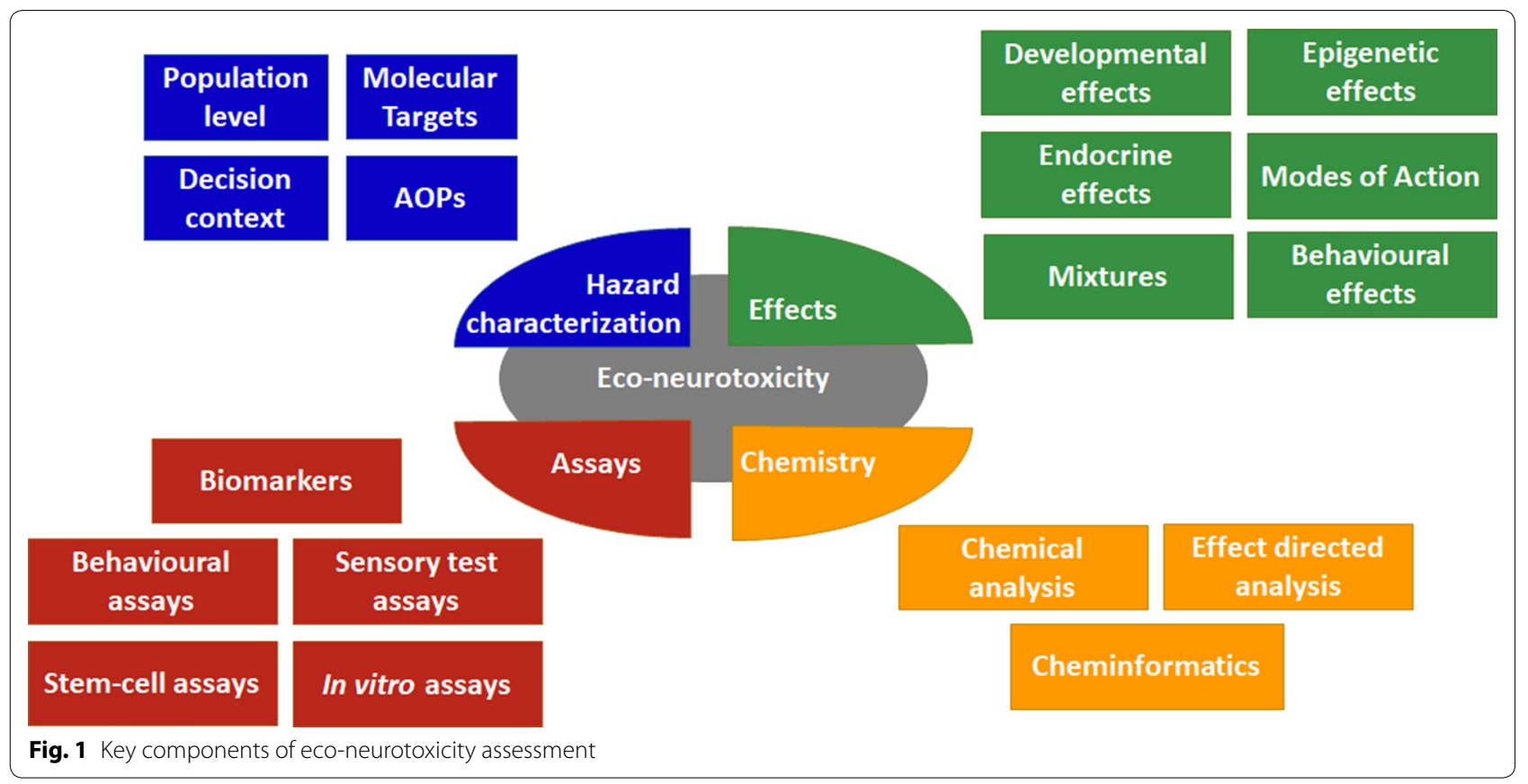


released again from the complex. In contrast the aged complex is fairly stable, and recovery is mainly due to new formation of AChE. In parallel to activation and inhibition, both diazinon and diazoxon can be detoxified by carboxylesterases and the resulting pyrimidinol can be conjugated prior to elimination.

As detoxification is the dominant pathway in mammals and oxidation is the dominant pathway in invertebrates, organophosphate insecticides are typically more toxic to invertebrates [117] than to vertebrates [118]. Differences in species sensitivity have been explained by the interplay between activation by oxidation and detoxification. The fish carp was found to be less sensitive than other fish species (trout, guppy, zebrafish) despite a more sensitive AChE site because it had the most active detoxifying enzymes [119]. Daphnia magna was found to be more sensitive to diazinon than Gammarus pulex, partially due to a six times slower detoxification by carboxylesterases, which compensated for the twice faster oxidative activation in G. pulex, but mainly due to toxicodynamic differences as observed by applying a toxicokinetic-toxicodynamic (TK-TD) model to survival data for G. pulex and D. magna [120]. TK-TD models are especially suitable to investigate the timedependent effects and complex mechanism of AChE inhibitors and allow estimation whether toxicokinetic or toxicodynamic parameters determine the overall effect [121]. Interestingly, for some organophosphate insecticides, the organism recovery is the rate-limiting step of toxicity [121]. For an uncoupler such as penta chlorophenol, the TK depuration and the TD organism recovery in G. pulex are 2 and 3 days, respectively; hence, the organism has basically recovered when it has eliminated the chemicals. However, this is different for carbaryl, chlorpyrifos and diazinon with a TK depuration of 1.4-11 days but a much longer organism recovery in the range of 15-28 days [121]. Hence, the sequence of exposure matters when mixtures are investigated over a time period [122].

Such detailed studies about the uptake, metabolism and excretion of neurotoxicants are extremely important as they help to link exposure to effects which is necessary to properly assess eco-neurotoxicity for different species.

\section{In vitro eco-neurotoxicity approaches}

As mentioned above, the research field of neurotoxicology is mainly focused on the potential effects of chemicals on development, structure and function of the human nervous system. There is general agreement within the field of toxicology that state-of-the-art toxicity testing includes tiered testing strategies that focus on the pathways that are critical for adequate functioning of cells, organs, and organisms, using different testing strategies to collect information on exposure and toxicity. This includes an emphasis on non-animal models, including integrated genomic and proteomic analyses of chemical-induced effects. This principle is embraced in the neurotoxicology research field and many efforts are focusing on developing and optimizing non-animal test systems to model such effects by increasing their sensitivity and specificity [123].

Non-animal test systems to test neurotoxicity include small intact organisms (zebrafish embryos, C. elegans), brain slices, cell lines, primary cell models and stem-cell derived models as well as assays assessing the inhibition of the bare enzyme (e.g. in the case of AChE inhibition assays) [124]. Different types of model systems have their own advantages and disadvantages related to multicellular complexity, ease of culture, variability between cultures, possibilities with regard to differentiation or genetic modification, species and costs. Test systems with non-mammalian test organisms $[125,126]$ may include ecotoxicologically relevant species, or methods to study the neurotoxicity endpoints may be modified to enable an application for other species.

Many neurotoxic mechanisms can be studied in vitro using biochemical and morphological endpoints that have the potential for medium-to-high-throughput testing. Parameters to investigate neuronal network functionality include network formation, action potential generation, calcium homeostasis, synaptic transmission, and synaptic plasticity. However, these assays were developed with the aim of studying effects of chemicals on the human (mammalian) nervous system and not on wildlife. Nevertheless, if the goal is to investigate whether neuroactive chemicals or chemicals with neurodevelopmental toxicity potential are present in the aquatic environment, these in vitro cell systems may also be suitable for water quality monitoring. Both ecotoxicological model species and in vitro bioassays for molecular mechanisms are included in the Smart Integrated Monitoring (SIMONI) framework for water quality monitoring [127].

Innovative experimental approaches are available to investigate effects on neuronal function, such as optical and electrophysiological measurements of intra- and intercellular signalling (calcium signalling, neurotransmitter release and post-synaptic receptor function) in cell models to measurements of spontaneous activity or network activity in neuronal networks using multi-electrode arrays (MEAs) [124]. Chemical-induced changes in network function measured in a MEA system may be due to changes in electrical activity as well as in the release or reception of intercellular signals. MEA systems thus provide an integrated, but not pathway specific, measure for effects on neurotransmission. Efforts are ongoing to increase throughput by using multi-well MEA systems. 
Primary (rodent) cell cultures can be used for routine neurotoxicity testing [128], and efforts are ongoing to increase throughput capacity of functional neuronal networks of (human) embryonic stem cells and neural/neuronal progenitor cells $[129,130]$. The generation of large amounts of data, either by testing many samples using high-throughput approaches or by generating high density data (e.g. using MEAs or optical recordings), requires ample data storage. The resulting challenges associated with data analysis require the implementation of chem/ bioinformatics approaches.

If the aim of effect-based monitoring is to study the impact of neuroactive chemicals, or chemicals with neurodevelopmental toxicity potential, on ecologically relevant species, it is critical to consider (dis)similarities in brain development, structure and function between mammals and ecotoxicologically relevant species. Considerable underlying differences may exist between mammals and other taxa in sensitivity to neurotoxic chemicals [131]. For example, it is well known that, due to interspecies differences in kinetic parameters of $\mathrm{AChE}$, insects are more sensitive to organophosphate insecticides than mammals [132]. Moreover, sensitivity to neurodevelopmental effects resulting from exposure to chemicals depends critically on the phase of mammalian brain development [33]. Specific sensitivity for neurotoxicity dependence on exposure timing may need to be investigated further using ecotoxicological model species. Additionally, neuronal network function depends critically on the presence of multiple cell types [133], including neurons, oligodendrocytes, microglia and astrocytes. The importance of multiple cell types for eco-neurotoxicology may depend on the endpoint of interest. It is thus required to identify the most relevant neuronal cell types and the impact of absence or presence of other cell types in the in vitro test system under consideration.

Due to the complexity of neurotoxic and neurodevelopmental mechanisms, and in view of potential differences between mammals and other species, it is recommended to develop a specific test set of chemicals for eco-neurotoxicity (including, for example, water relevant chemicals and model chemicals that affect relevant mechanisms) for (interlaboratory) studies to test candidate in vitro bioassays (e.g. based partly Aschner et al. [134]). Emerging techniques and innovations in neuroscience and neurotoxicity should be closely followed and assessed for their potential and applicability in ecotoxicological water quality monitoring.

\section{Stem cells in eco-neurotoxicity}

In the area of neurotoxicity and developmental neurotoxicity testing, the use of pluri- and multipotent stem cells differentiating into diverse neural cell types as well as standardized methods for differentiation will lead to an improved understanding of chemically induced adverse reactions. In contrast to cell lines or primary cells, stem cells and their derivatives are neither genetically transformed nor easily lose their tissue characteristics. However, differentiation conditions need to be strictly controlled to prevent differences in cell characteristics between cultures, which calls for appropriate control conditions to be included in toxicological testing procedures with stem cells. Neural differentiation occurs early in development and the formation of glial cells and neurons can quite easily be mimicked in vitro [135-138]. Thus, stem cells facilitate high-throughput neurotoxicity testing on a wide range of neural cell types. In this context, human induced pluripotent stem cells (iPSCs) have the potential to play an important role in predicting human-specific neurotoxicity and DNT [139]. Stem cell derived neuronal and glial models allow MoA-based DNT testing [37]. In recent years, the number of studies using stem cells for neurotoxicity and DNT testing with a variety of endpoints increased considerably. Many representative studies investigating neurotoxicity or DNT of drugs using stem cells applied endpoints such as cellspecific cytotoxicity (apoptosis, necrosis), cell migration, intracellular $\mathrm{Ca}^{2+}$ levels, disordered differentiation, neurite and dendrite outgrowth, neural network formation and activity, as well as synaptogenesis and synaptic activity [140-145]. Furthermore, 3D models such as neurospheres are now available and provide an improved comparability to the in vivo situation. Progress on in vitro 3D brain models has also been achieved [146]. 3D brain organoids derived from pluripotent stem cells are promising experimental models for brain development, DNT testing and neurodegenerative disorders enabling mechanistic pathway and stage-specific studies [147]. Despite this good progress in neurotoxicity and DNT testing with stem cells, validated methods for several endpoints still have to be established.

Mechanisms employed in the in vitro stem cell neurotoxicity and DNT testing are in general highly conserved in evolution. Results based on highly conserved mechanisms can be transferred to a variety of species, including aquatic organisms.

By now, many protocols for generating specific neuronal populations of different areas of the brain and peripheral nervous system using human iPSCs are available, and their efficiency is continuously increasing [148]. To date a general problem is that the protocols generate a heterogenous population comprised of the specific neurons they aimed for and also other cells, which may have a different identity. This increases the variability of potential test readouts. Also, especially for peripheral neurons, 
very long maturation times are needed to generate mature neurons, and tests performed at an earlier time point may be disturbed by the immature cellular answer of some of the cells. Additionally, some protocols suffer from a low reproducibility and relatively high variability. Thus, many repetitions are need, which renders the potential tests time and cost intensive. Current research is focusing on improving these shortcomings, and one solution is already in use: differentiating iPSCs into neuronal precursor cells offers the possibility to freeze and store larger amounts of cells of one differentiation, which then can be defrosted for the tests. This has the advantage that several tests can be run with the cells that were generated at the same time, at least until the precursor state. In most protocols for neuronal differentiation, many cells are lost during the first few days, thus making it hard to predict the cell number resulting from a single differentiation, even though a constant number of iPS cells were used. Now, one can defrost neuronal precursor cells and use a specific number of these cells for the last steps of the differentiation protocols, during which cell loss is almost negligible. This approach allows for a better control over the total number of generated neurons, thus increasing the comparability between different sets of tests.

Using gene-editing and other genetic methods progenitor cells can, e.g. be transduced to stably express Ngn2 under a Tet-On Advanced transactivator, allowing differentiation to be switched on by adding tetracyclin [149].

Apart from mice and rats, which often serve as model systems for human diseases, iPSCs from other mammals, such as farm animals [150], pets such as dogs [151] or endangered wild animals such as felids or orangutans $[152,153]$ are reported and offer a whole new set of opportunities to study the impact of environmental toxicity on their physiology.

A drawback of iPSCs is that the cells lose their epigenetic signature during reprogramming. To overcome this problem, somatic cells were used to transdifferentiate into neurons, bypassing the iPSC-state. Although to date the yield of this method is low and protocols show high variability, this allows to study age-dependent effects and may be a worthy option for eco-neurotoxicity testing in the future (see, e.g. collection of papers here: [154]).

\section{Cell-free neurochemical methods}

Cell-free neurochemical assays are simplified in vitro systems that may help evaluate the effects of a test chemical on neurobiochemical processes. Cell-free assays are performed with cell lysates, tissue homogenates or with purified membranes (but not with living cells) and give information about direct biochemical interactions between test molecule and biological targets like receptors. They form an important assay category within the US-EPA's ToxCast program and show promise for use in ecotoxicology as discussed by Arini et al. [155]. A great advantage, for example, is that they are amenable for use from any species from which brain tissue can be obtained, with one study comparing responses across 20 species of fish, mammals and birds [156]. Besides studying chemicals, cell-free assays have also been used to screen extracts from real-world samples including pulp and paper mill effluents [157] and wastewater effluents [158].

\section{Sensory system tests in eco-neurotoxicity}

Neurotoxic effects on sensory systems are mostly studies in vertebrates. Little is known about effects in invertebrates. Sensory structures receive information from the environment and transduce it into a signal recognizable to the nervous system. The information or stimuli can be of different modality including light, sound, smell, taste, pressure and temperature. Generally, receptive cells contain transmembrane receptors which undergo a conformational change upon stimulation. A signal transduction cascade leads to the opening of ion channels and concomitant membrane potential changes, thereby creating an action potential. Many behaviours like feeding, mating, predator avoidance, migration, social interaction and communication are crucially informed by sensory systems. Thus, their impairment can have severe impact on fitness and survival of an animal.

Environmental contaminants such as pharmaceuticals, pesticides and heavy metals have been shown to interfere with the sensory structures of different species including humans and fish, thereby creating deficiencies in sensation and behaviour. Behavioural output is an increasingly measured, ecologically relevant and very sensitive endpoint. To localize specific sensory impairments within the nervous system using behaviour is, however, challenging because behaviour is the integrated output of multisensory, neuroendocrine and neuromuscular signals, and tests are often not specific enough (e.g. impaired feeding might result from motor deficits, impaired olfaction, impaired vision or a combination thereof).

Generally, four techniques listed in Table 1 are applied to assess the different sensory systems like, e.g. olfaction, vision and mechanosensation (discussed below). While all of them have their advantages and drawbacks, there is no recommendation as to which one is the best. Rather, tests have to be tailored to the study purpose and a multidisciplinary integrated approach is necessary to fully understand neurotoxicity mechanisms [2]. 
Table 1 Techniques to test sensory system

\begin{tabular}{|c|c|c|c|c|}
\hline & Sensitivity & Throughput & Specificity & Remarks \\
\hline Electrophysiology & +++ & + & +++ & Link to behaviour often unclear, sophisticated preparations needed \\
\hline Behaviour & ++ & +++ & + & $\begin{array}{l}\text { Multisensory input; depends on proper locomotor function; high } \\
\text { ecological relevance }\end{array}$ \\
\hline Anatomical changes & + & ++ & +++ & Only apparent when sensory function already impaired \\
\hline Molecular markers & $+/+++^{*}$ & +++ & $+/+++^{*}$ & Good sensory toxicity markers are still rare \\
\hline
\end{tabular}

* Depending on marker

\section{Olfaction}

In fish, the olfactory system is particularly vulnerable to neurotoxic contaminants because of the direct contact of olfactory sensory neurons with the surrounding water. Reduced or absent ability to smell (hyposmia or anosmia) have been shown to occur upon exposure to metals, pesticides and other contaminants like, e.g. surfactants [159]. The classical method to assess olfactory impairment is by electro-olfactography [160]. It assesses electrophysiological changes in olfactory sensory neurons by extracellular recordings. Olfactory behavioural tests include either attraction to food extract, avoidance of skin extract or attraction/avoidance of the chemical itself [159]. Notably, while the zebrafish olfactory system offers several experimental advantages to study sensory neurobiology in general and olfactory neurotoxicity in particular, there are a number of profound differences that might render translation of results from such studies to other species.

Among the major advantages of the zebrafish model are (i) identified ecologically relevant classes of natural odours such as amino acids and bile acids [161, 162]; (ii) cultivation of the adult zebrafish head ex vivo without anaesthesia, allowing neurophysiological measurements in the intact brain [163]; (iii) comparably small brain size that provides access to larger fractions of neurons by multiphoton microscopy [164] - a fact particularly true for the zebrafish olfactory system, which contains relatively few neurons and glomeruli [165]; and (iv) large detailed data at both the single neuron and population level that allows realistic mathematical simulations of circuit function [166]. Moreover, at first glance, the zebrafish olfactory system contains molecular and cellular constituents that appear similar in organization to the rodent olfactory system, thus, providing an attractive vertebrate model system to investigate the mechanisms underlying olfactory system development and function. However, the fish olfactory epithelium is of a "mixed" type, containing two major types of olfactory sensory neurons, i.e. ciliated and microvillous neurons. Both express distinct types of chemosensory receptors, project to different brain regions and likely mediate different behaviours [167]. Moreover, the three canonical zebrafish chemosensory gene families (or, taar and olfC/V2r) are somewhat unique and quite distinct in size and relative proportions to those of most tetrapods (indicative of the divergence of both lineages $\sim 430$ million years ago [168].

The mouse has become the most widely used model system in olfactory research based on established protocols for genetic manipulation. An important distinction between the olfactory systems in fish and mice is stimulus delivery. While the fish olfactory organs are exposed to pollutants and xenobiotics that are dissolved in water, rodent noses constantly sample volatile air-borne chemicals at minute concentrations. Thus, the range of potentially hazardous chemicals that water-living species like fish are naturally exposed to will be dramatically different from the repertoire of potential harmful compounds that land-living species like mice encounter (and vice versa). The olfactory system's remarkable capacity to renew upon perturbation also needs to be taken into account [169]. The olfactory epithelium has extensive neurogenic and regenerative capacity in both rodents and humans that persists throughout adult life and is unmatched elsewhere in the nervous system [170]. Cells within the basal epithelial layer function as neuronal precursors, multipotent progenitors and/or stem cells. However, the niche signals that control the self-renewal and differentiation of these basal cells are not well understood [170]. This regenerative capacity will strongly impact eco-neurotoxicological assays that target the olfactory system. Accordingly, the system's vulnerability will, at least to some extent, be compensated by adult neurogenesis.

Few neurotoxicological assays have been developed using mice. This is somewhat surprising given the large body of knowledge available, established animal care facilities, comparably short generation turnover and the large translational promise that rodent model systems offer. Thus, it appears likely that future eco-neurotoxicology assays will utilize a pipeline that spans cell-based in vitro experiments, high-throughput behavioural assays in zebrafish and other ecologically relevant species.

\section{Vision}

About 3000 chemicals are toxic to the human eye and visual system [171]. Retinotoxic effects for organic 
solvents and metals have been described, not only for humans [172] but also for fish [173-176], for which most literature focuses on effects of methylmercury and ethanol. Moreover, the fish retina was affected upon herbicide $[177,178]$ and pesticide exposure [179] and was shown to accumulate cocaine [180]. Electrophysiological measurements of retinal function are called electroretinograms. They record the retinal sum field potential to a visual stimulus [181] and are applied in many species including fish [182]. Visual behaviour tests for fish are well developed, even to the point that different visual properties like motion detection, colour detection and discrimination, object recognition and visual acuity can be tested [183]. A popular assay is the measurement of optokinetic reflex, in which the animal is presented a moving grating which it follows with accurate eye movements. Impaired visual function results in reduced or absent eye movements [184, 185]. Although both techniques are widely established in zebrafish models for human ocular diseases [186], toxicant-induced impairments of visual function are only scarcely studied. Instead, retinotoxic effects are mostly assessed based on rather insensitive endpoints like histology or eye size (e.g. microphthalmia $=$ smaller eyes).

\section{Mechanosensation}

Hair cells are sensory cells of the vertebrate inner ear and the lateral line system of aquatic vertebrates. They transduce pressure changes in the surrounding medium into a neuronal signal as a result of deflection of their cilia, which leads to the opening of ion channels, enabling the detection of acoustic stimuli and hydrodynamic flow. Many drugs such as aminoglycoside antibiotics, platinum-based anti-cancer drugs, anti-malarics or nonsteroidal anti-inflammatory drugs are known to induce ototoxicity in humans (see references in [187]), for the most part irreversible. In fish, some of these drugs equally cause ototoxicity and damage to the lateral line [188]. Moreover, metals such as copper, cadmium and others have been shown to cause hair cell death and deficits in behavioural responses in zebrafish $[189,190]$ and other fish [188]. Behavioural responses to acoustic stimuli [191-193], responsiveness to water motion [194] and rheotaxis (counter-flow swimming) [195, 196] have been measured to assess hair cell function. Moreover, vital dyes to stain hair cells have been widely used to assess the structure of lateral line hair cells in zebrafish [197]. Effects on the lateral line hair cells are one of the most promising sensory endpoints because of their great accessibility, amenability for staining's and dyes and straightforward implication in rheotactic behaviour [198]. Another method to assess hearing abilities in fish is sound-evoked potential audiometry, which measures field potentials in response to an auditory stimulus using cutaneous electrodes [199].

In order to assess the full neurotoxic potential of environmental pollutants, a combination of tests and the assessment of multiple sensory systems are necessary to precisely localize effects within the nervous system [2, 200]. Future studies should strive to increase our mechanistic understanding of chemical neurotoxicity, which would help predicting eco-neurotoxicological effects. In this respect, model organisms such as the zebrafish are very helpful, because a large variety of genetic tools and genomic resources are available and many tests are already established for the analysis of human brain disorders [98], but they are not yet fully adopted for neurotoxicity testing. Additionally, emerging neuroscience techniques such as in vivo 2-photon calcium-imaging of neuronal activity [201-203] or optogenetics [204] might hold underexplored opportunities for the mechanistic dissection of complex neurotoxicological processes. Moreover, large-scale toxicity screenings using the zebrafish model has been implemented in the framework of ToxCast and Tox21 [205-208], but more efforts are needed to increase the specificity of tests for sensory neurotoxicity in larval zebrafish and implement them in a high-throughput manner in order to keep pace with toxicity testing of the vast number of newly registered chemicals.

\section{Biomarkers of eco-neurotoxicity}

Biomarkers are defined as molecular, biochemical, cellular and physiological changes, caused by external stress factors. The two mostly discussed groups of biomarkers are: biomarkers of exposure that allow statements about the quality and/or quantity of exposure, whereas biomarkers of effect allow statements about effects and the health status of exposed organisms [209]. Classical examples for the first category are metallothioneins, which indicate metal contamination [210]. A typical biomarker of effect is the induction of stress proteins (heat shock proteins) [211] or a decrease of lysosomal stability [212]. With the latter two one can tell that the organism was exposed to environmental stressors, but it is not possible to tell, which stressor or contaminant exactly caused the observed effect [209]. Biomarkers can either be measured invasive/destructively, e.g. by determining enzyme inhibition in brain or whole-body homogenates or nondestructively, by determining the biomarkers of interest, e.g. in blood, mucus or skin samples [213, 214].

Biomarkers of eco-neurotoxicity include parameters reacting specifically to neurotoxic chemicals. The most well-known biomarker of effect for neurotoxicity is the measurement of AChE inhibition. This is the primary mechanism of action of organophosphate and carbamate 
insecticides. Enzyme activity is quantified in brain or whole-body homogenates of exposed organisms, and compared to reference inhibitors, as has been shown, e.g. for zebrafish embryos [215], fish [216] and Daphnia magna [217]. In addition, non-destructive measurement of cholinesterase is possible, e.g. by determining butyrylcholinesterase in blood serum [218, 219]. Alternatively, commercially available isolated $\mathrm{AChE}$ can be used to test chemicals and complex environmental mixtures such as water samples. The tests applied are typically based on the Ellman assay [220], which is a colorimetric assay that detects the hydrolysis of the substrate acetylthiocholine. Despite its wide application in water quality assessment, the assay using isolated AChE should be used with caution because concentrations of organic matter as low as $2 \mathrm{mg}_{\mathrm{C}} / \mathrm{L}$, when present in solid-phase extracts of typical surface water, can act as non-specific inhibitor of AChE [221]. This can lead to an overestimation of insecticidal activity in ambient samples. The application of cholinesterase biomarkers for environmental monitoring has been reviewed by Mineau [222].

Other biomarkers of eco-neurotoxicity involve key neurotransmitter pathways and the measurement of corresponding enzyme inhibition or receptor activity, i.e. neurochemical biomarkers. Apart from AChE and the corresponding nicotinic and muscarinic receptors, activity of monoamine oxidase with dopamine or serotonin receptors, GABA transaminase with GABA(A) and $\mathrm{GABA}(\mathrm{B})$ receptors as well as glutamic acid decarboxylase and glutamine synthetase with the receptors NMDA, AMPA and Kainate can be determined. These biomarkers have been applied in studies on a variety of organisms such as worms, bivalves, fish, mammalian wildlife and birds (for review see [38]). For example, documented measurements have included a decrease in serotonin levels and an increase in monoamine oxidase levels in caged mussels in a river downstream of wastewater treatment plants effluent [223]. If mussels were exposed to primary treated and ozonated effluents in a flow-through experiment, GABA levels as well as the activities of several neuroactive enzymes (glutamic acid decarboxylase, monoamine oxidase and $\mathrm{AChE}$ ) were reduced and levels of serotonin and dopamine increased [224]. With regard to fish, the application of biomarkers of eco-neurotoxicity has been reviewed in several publications [2, 225, 226]. In juvenile rainbow trout, altered brain neurotransmitter metabolism after exposure to $\beta$-naphthoflavone and benzo(a)pyrene resulted in impaired availability of serotonin at short term (after $3 \mathrm{~h}$ ) and increased neuronal metabolic utilization of serotonin and dopamine after 24 and $72 \mathrm{~h}$ [227].

For any study, it has to be taken into account that the flexibility (plasticity) of the nervous system, as well as the age and developmental stage of the investigated organisms, may play an important role in the measured responses [38].

\section{Behavioural screening tests}

For aquatic eco-neurotoxicological screenings, behavioural toxicity tests in small organisms may be of special interest. Behaviour is an understudied but sensitive and ecological relevant endpoint in ecotoxicity testing for all kinds of different species. Several studies reported effects on behaviour at concentrations orders of magnitudes below lethal concentrations [228, 229]. Behaviour is the integrated response of the conditions to which an organism is exposed. A variety of activities are used as behavioural endpoints to screen for effects of chemicals, for example avoidance, feeding and locomotion [1]. Some of these behavioural endpoints may be applicable to investigate rapid acute neurotoxic responses or effects of longer exposures with consequences that may have larger impact, such as neurodevelopmental effects. Such effects on behaviour may be caused by acute neurotoxic effects on neuronal functioning (inter- and intracellular signalling and neuronal network function to receive, conduct, and transmit signals via chemical or electrical synapses and relay information between specific brain regions for information processing as well as learning and memory formation) or to mechanisms related to neurodevelopmental processes (proliferation, migration, differentiation, formation of axons, and dendrites, synaptogenesis, network formation and apoptosis). Automated behavioural analysis technologies allow medium-to-highthroughput assessments.

Part of behavioural disruptions resulting from chemical exposure may rely on direct neurotoxicity or parental transfer, but beyond this direct relationship, behaviour is an interesting endpoint because it may also be an integrative indicator of several other physiological issues, e.g. metabolism, sensory organs, morphology or molecular pathways alteration.

\section{Behavioural test with laboratory fish species}

The fact that behavioural responses may be integrative indicators of many physiological issues explains the rapid expansion of behavioural studies in ecotoxicological research during the last decades, particularly those using fish early life stages (ELS). Indeed, fish ELS are very amenable to high-throughput monitoring evaluation in multi-well plates. With that system behaviour like basal activity, response to a light change or other stimuli (indicative of anxiety) can be assessed. For the photomotor response test with zebrafish embryos, it has been even shown that different compound groups induce different behavioural profiles which mean the test can be 
used to identify neurotoxic MoAs of compounds [230]. In addition, the possibility of using behaviour as a complementary approach to common fish embryo toxicity (FET) tests has recently been explored, demonstrating a significantly higher sensitivity of behaviour EC50 compared to FET LC50 for some compounds [231]. ELS have, however, a limited behavioural repertoire which is partially linked to a lower level of nervous system maturation compared to older stages. For example, it appears that learning associated with classical and operant conditioning is not efficient in zebrafish before 3 weeks of age, which is roughly the end of the larval stage [232]. In addition, and partly related to this limitation, the predictability of late outcomes from behavioural disruption in ELS is not obvious. As an example diquat, one of the compounds tested by Kluver et al. showed no behavioural disruption in ELS while it induced hyperactivity in older larvae [233].

Juveniles or adults have a much larger behavioural repertoire and/or cognitive abilities, which can easily be divided in behavioural units and evaluated. Behavioural disruptions resulting from exposure to organic pollutants, including PAHs or PCBs have been characterised using long-term dietary exposures to environmental mixtures. An increase in psychological stress is a common trait observed relating to all examined pollutants [234]. In case of PAHs, a decrease in the neurotransmitter serotonin could be the driver for this behavioural change [235]. More recently, behavioural changes in the offspring of fish exposed to a mixture of PCBs and PBDEs showed that even if exposed parents displayed no change in behaviour, two offspring generations showed a significant increase in anxiety as adults while behaviour of larvae was modified in up to four offspring generations.

\section{Behavioural tests with non-fish species}

Van der Geest et al. showed that changes in ventilation behaviour of fifth instar larvae of the caddisfly Hydropsyche angustipennis occurred at approximately 150 times lower copper concentrations than mortality of first instar larvae [229]. Avoidance behaviour of the amphipod Corophium volutator to contaminated sediments was 1000 times more sensitive than survival [236]. Chevalier et al. tested the effect of twelve compounds covering different toxic MoA on the swimming behaviour of daphnids and observed that most compounds induced an early and significant swimming speed increase at concentrations near or below the $10 \%$ effective concentration $(48 \mathrm{~h}$ ) of the acute immobilization test. A reduction in defence and orientation behaviour of rusty crayfish after exposure to nicotinoid pesticides below morphological effect concentrations was observed by Sohn et al. [237]. The clam avoidance behaviour (closing valve after trigger) is suggested as a fast and easy screening tool for neurotoxicants [238]. Diamesa zernyi larvae from the wild also showed altered swimming behaviour after exposure to contaminants at low effect concentrations [239]. These examples and numerous others all showed that organisms may exhibit altered behaviour at relatively low and therefore often environmentally relevant toxicant concentrations [240]. Behavioural responses to toxicant exposure can also be very fast, allowing organisms to avoid further exposure and subsequent bioaccumulation and toxicity. A wide array of such avoidance responses have been incorporated in ecotoxicity testing [28, 241], including the avoidance of contaminated soil by earthworms (Eisenia fetida) [242], feeding inhibition of mussels (Corbicula fluminea) [238], aversive swimming response to silver nanoparticles by the unicellular green alga Chlamydomonas reinhardtii [243] and by daphnids to twelve compounds covering different toxic MoA [240].

\section{Field studies}

Field studies are the most relevant approach to evaluate disruption resulting from chemical exposure but have drawbacks since it is (currently) almost impossible to disentangle the consequences of chemical exposure from other stressors such as food deprivation or environmental changes other than chemicals. On the other hand, laboratory experiments generally using optimal conditions except for the chemical exposure may lead to an underestimation of these exposure effects. They allow, however, the establishment of a potential direct link between exposure and physiological effects, including behavioural disruption. Indeed, behavioural abilities condition individual survival and fitness and hence have consequences at the population level. In the environment, behaviour abilities are important, e.g. to find food, to escape predators, to find new territory or partners for mating. All these behaviours are complex and rely on simpler so-called behavioural units, which are of ultimate importance in behavioural ecology because they are what can be measured [244].

Subtle changes in animal behaviour may affect trophic interactions and ecosystem functioning. Langer-Jaesrich et al. reported that midge larvae (Chironomus riparius) exposed to chlorpyrifos, a neurotoxic insecticide, showed a decrease in burrowing behaviour, resulting in an increase in the feeding rate of zebrafish preying on these exposed chironomids [245]. However, when exposing predators and prey simultaneously, no significant differences in the feeding rate of zebrafish were observed, suggesting impairment in prey recognition of the exposed zebrafish. In a laboratory toxicity experiment Hunting et al. (2013) observed that endpoints representing 
ecosystem structure and functioning, like bacterial diversity, bacterial activity and decomposition, responded much more sensitively to copper exposure than survival of the isopod Asellus aquaticus [246]. Monitoring the behaviour of the isopods by measuring the redox potential of the first upper $\mathrm{cm}$ of the sediment revealed that, although the isopods did not suffer from mortality upon the copper exposure, they became completely inactive. The lack of locomotion and shredding activity of the isopods caused the ecosystem processes to cease.

Since behavioural responses can be very fast, they can also be employed in early warning systems, with manifold applications. These so-called online-biomonitoring systems are installed to monitor the water quality permanently, and if the animals show an abnormal behaviour, an alarm goes off. This allows, for instance, the cessation of water intake for drinking water preparation. One of the most widely applied online-biomonitoring system is the Multispecies Freshwater Biomonitor ${ }^{\mathrm{TM}}$, based on a non-optical recording principle, the quadrupole impedance technique for several aquatic and sediment in/vertebrate species. This device quantitatively records behavioural patterns in a fully automated way on a real-time basis $[247,248]$. Another approach uses fluorescence emissions and can be used to measure chlorophyll and thereby monitor phytoplankton biomass [249]. Daphnia and fish behaviour can also be monitored using cameras [250]. The valve opening of clams can be monitored using attached electrodes [251]. Behaviour is a fast and sensitive endpoint to toxicant exposure, allowing e.g. avoidance behaviour to be incorporated in online-biomonitoring systems. Subtle changes in animal behaviour may affect trophic interactions and ecosystem functioning, underlining the importance of incorporating behavioural endpoints into ecotoxicity testing.

\section{Mixture toxicity}

The last decades have seen steadily rising volumes and numbers of industrial chemicals. Many of these substances are released into the environment, and thus, contamination comprises a mixture of different chemicals, each posing different characteristics and potential toxic responses towards humans and wildlife. Moreover, the large number of untested industrial chemicals and transformation products hampers comprehensive risk assessment of complex real-world mixtures of toxic chemicals. Regularly, contaminated environmental samples contain high numbers of many different pollutants which makes it an analytical challenge, including workup, separation, detection and quantification. Therefore, it is also difficult to assess the myriad of putative mixture effects and unknown toxic effects of old, new, and emerging chemicals in biological systems [252]. Additionally, the concentrations of pollutants in environmental samples are diverse and most of the time site-specific. This will cause also different biological response depending not only on the presence of certain pollutants but also on their relative composition [253]. One practical implication of this in connection to contaminated sites is that risk assessments still mainly rely on chemical analysis. However, such analysis does not always provide any information regarding the interactions between chemicals, including their integrated toxicological effects on organisms. Particularly, under regular environmental conditions organisms are exposed to multiple chemicals associated with different risks and the underlying toxic responses may generate toxic effects at levels exceeding the combined effects of single compounds. Thus, it has been recommended that combination effects of the entire mixture of contaminants should be evaluated in risk assessments [254, 255]. Therefore, many different toxic effects need to be checked. The neurotoxic potential of environmental chemicals presents a serious threat since they can, for instance, alter the behaviour of organisms. However, guidelines for neurotoxicity assessment consider only mammals and birds, and, thus far, there is no regulatory framework for neurotoxicity assessment in aquatic systems. DNT, which evaluates effects on the developing nervous system of foetuses, larvae, and juveniles, has special relevance for environmental risk assessment due to the ecological importance of early stages for recruitment and maintenance of natural populations. Despite this, DNT testing is currently required for human health risk assessment only and involves labourintensive, time consuming and expensive animal testing. Consequently, few chemicals have been tested for DNT, leaving the potential impacts of untested chemicals and their combined effects unknown [256, 257]. Particularly, many pesticides are well known to act as neurotoxic compounds and commonly occur as complex mixtures in aquatic systems but concentrations are often low. Populations and communities of different species, however, can be dramatically impacted by low concentrations of pesticides, e.g. $[258,259]$. Moreover, it is well known that pesticide mixtures contain compounds with similar and dissimilar MoAs [260] that can cause either concentration additive, synergistic neurotoxicity as well as unpredicted mortality depending on the combinations of different pesticides [260-262]. As a consequence, for chemicals with the same MoA, it might be possible to estimate their combined neurotoxicity using common models. However, known neuroactive compounds detected in the environment, such as pesticides, pharmaceuticals and heavy metals, occur together with thousands of chemicals of unknown neurotoxic potential, with different MoAs, and often in low concentrations. 
Therefore, there is a great demand for the development of meaningful effect-based methods to be applied for the screening and investigation of the neurotoxicity of chemicals and their combined effect.

One approach to identify/prioritize toxic compounds in mixtures is using toxic pressure modelling. Toxic pressure is the probability that measured field concentrations will be above laboratory effect concentrations causing adverse effects to an ecosystem [263]. The toxic pressure gives an indication what species might be affected by environmental contaminations. To calculate the toxic pressure, chemical analyses of compounds are used together with corresponding laboratory data. The toxic pressure of a mixture is determined by quantifying the potentially affected fraction (PAF) using species sensitivity distribution modelling for each compound in the mixture. In the following, mixture modelling is applied to estimate the mixture toxic pressure [264]. This method can be used either to calculate water quality standards, to prevent adverse effects or to predict potential effects of the current exposure situation by calculating the multiple-substances potentially affected fraction (msPAF). The program to calculate the msPAF or rank substances based on their toxic contribution is freely available [265]. To apply this method for eco-neurotoxicity risk assessment, laboratory data for neurotoxic effects for a variety of species are needed.

\section{Challenges in chemical analysis of neurotoxic compounds in environmental samples}

For describing the behaviour, fate and effects of neurotoxic substances in the environment, analytical methods providing sufficient selectivity and sensitivity are required to achieve limits of quantification in the $\mathrm{ng} / \mathrm{L}$ and $\mu \mathrm{g} / \mathrm{kg}$ range for water samples and biota, respectively.

The diversity in the chemical properties of neurotoxic substances requires a variety of analytical methods for their identification and quantification. Chromatographic separation techniques combined with mass spectrometric detection are largely used for determining organic trace substances. For the determination of neurotoxic substances in solids, advanced extraction techniques are usually required to separate the analytes from many organic matrix compounds prior to analysis.

For the determination of organic substances, liquid chromatography coupled to a mass analyser (LC-MS) is the most frequently used analytical method. Electrospray ionization (ESI) is a robust ionization technique for polar neurotoxic substances. The MS/MS technique is used to reduce the chemical background thus leading to better signal-to-noise ratios. In triple quadrupole mass spectrometers, the analyte ions are selected in the first quadrupole filter and fragmented in the second quadrupole (collision cell), whereas one or more produced fragment ions are selected and detected in the third quadrupole filter. This so-called multiple reaction monitoring (MRM) enables the determination of neurotoxic substances in water in the lower $\mathrm{ng} / \mathrm{L}$ range without any preconcentration techniques. For the analysis of biota, however, the much higher sample complexity (matrix) requires an increase in the selectivity of the mass spectrometer. One possibility to reach this is to replace the third quadrupole filter by a high-resolution mass analyser (HRMS). The time-of-flight (TOF) or Orbitrap technology is used in such hybrid instruments. A further benefit of using HRMS is the detection of all ions which are generated in the ion source. Thus, the datasets can be screened for substances which were initially not anticipated (so-called non-target screening).

In gas chromatography with mass spectrometric detection (GC-MS), the separation of analyte and matrix compounds (via the gas phase) usually takes place in capillary columns. Electron ionization (EI)-i.e. the interaction of energetic electrons with gas phase molecules-leads to ionization and fragmentation of analyte molecules. The fragment ions are subsequently detected.

For the analysis of metals, the preferred analytical methods are atomic absorption spectroscopy (AAS) or inductively coupled plasma mass spectrometry (ICP-MS). For determination of metals in solids, chemical digestion (e.g. $\mathrm{HNO}_{3} / \mathrm{H}_{2} \mathrm{O}_{2}$ ) is required. If the binding form or oxidation state of the metal should be retained during sample preparation, a suitable type of chemical digestion has to be selected. In this case, the ICP-MS is coupled with a separation method (e.g. ion chromatography).

\section{EDA in eco-neurotoxicity}

Tens of thousands of unknown chemicals and toxicants can be detected in environmental samples, but in many cases only a few chemicals are responsible for significant risks to the ecosystem [7]. The concentration of chemicals may be variable in time and space and may include known but also unexpected and unknown environmental pollutants [7]. Since a comprehensive analysis of the whole chemical universe is technically impossible, it is necessary to develop tools to reduce the complexity of environmental contamination and identify the key contributors to a specific effect [7].

Effect-directed analysis (EDA) was confirmed to be a powerful tool for the identification of chemicals causing effects to aquatic organisms or posing long-term risks such as endocrine disruption [266-268]. The EDA approach is based on the combination of chemical and biological tools isolating single substances or mixtures 
causing effects in laboratory bioassays. A typical EDA workflow (Fig. 3) follows certain steps starting with biotesting of specific effects in an environmental sample. If the bio-testing reveals toxicity, the complexity of the sample can be reduced by fractionation, and fractions without biological activity are eliminated. Several fractionation steps can be performed until the toxic fractions are sufficiently isolated to allow identification by target and non-target chemical analysis [7].

Despite the fact that neurotoxicity was confirmed to be one of the most important MoAs observed in environmental samples [9], the number of EDA studies focused on the detection of neurotoxicity and neuroactive compounds is still very limited. One important example is give in the study of by $\mathrm{Qu}$ et al. who identified in vitro neurotoxicity induced by brominated flame retardants in environmental samples [269]. They used a combination of cell-based assays, fractionation and liquid/gas chromatography coupled with mass spectroscopy (LC and GC-MS) for the identification of neurotoxic brominated flame retardants in different environmental matrices [269].

In vitro $\mathrm{AChE}$ inhibition tests are most frequently used as effect-based tools in EDA for the identification of neurotoxic chemicals in water samples [233, 245, 270, 271]. The AChE assay was used for the identification of 50 neurotoxic compounds in spiked surface water samples by using an innovative 2-dimensional thin-layer chromatography [272]. Ouyang et al. developed a high-throughput EDA method for the fast identification of AChE inhibitors in wastewater treatment plant effluents by using LCMS and a novel micro-fractionation workflow followed by an in vitro bioassay screening. This study successfully identified the presence of three potential AChE inhibitors (tiapride, amisulpride and lamotrigine) in environmental samples. It is important to underline that the in vitro AChE assay may still fail in the detection of causative neuroactive compounds during EDA studies and falsepositive results are often observed in in vitro testing, since many molecules may form unspecific bindings with the purified enzymes [271].

In this context, in vivo and organism-level methods were also successfully applied in a few studies for the identification of neurotoxicity in environmental samples. In particular, behavioural and molecular tools using zebrafish embryos were used with good outcomes in different EDA studies for the identification of anticonvulsant drugs and natural toxins in plant extracts [273-275].

Finally, scientists are currently also working on the implementation of high-throughput techniques that are potentially useful in EDA for the identification of neurotoxic chemicals [276, 277]. As a major example, Fabel et al. successfully developed a fast novel workflow for the

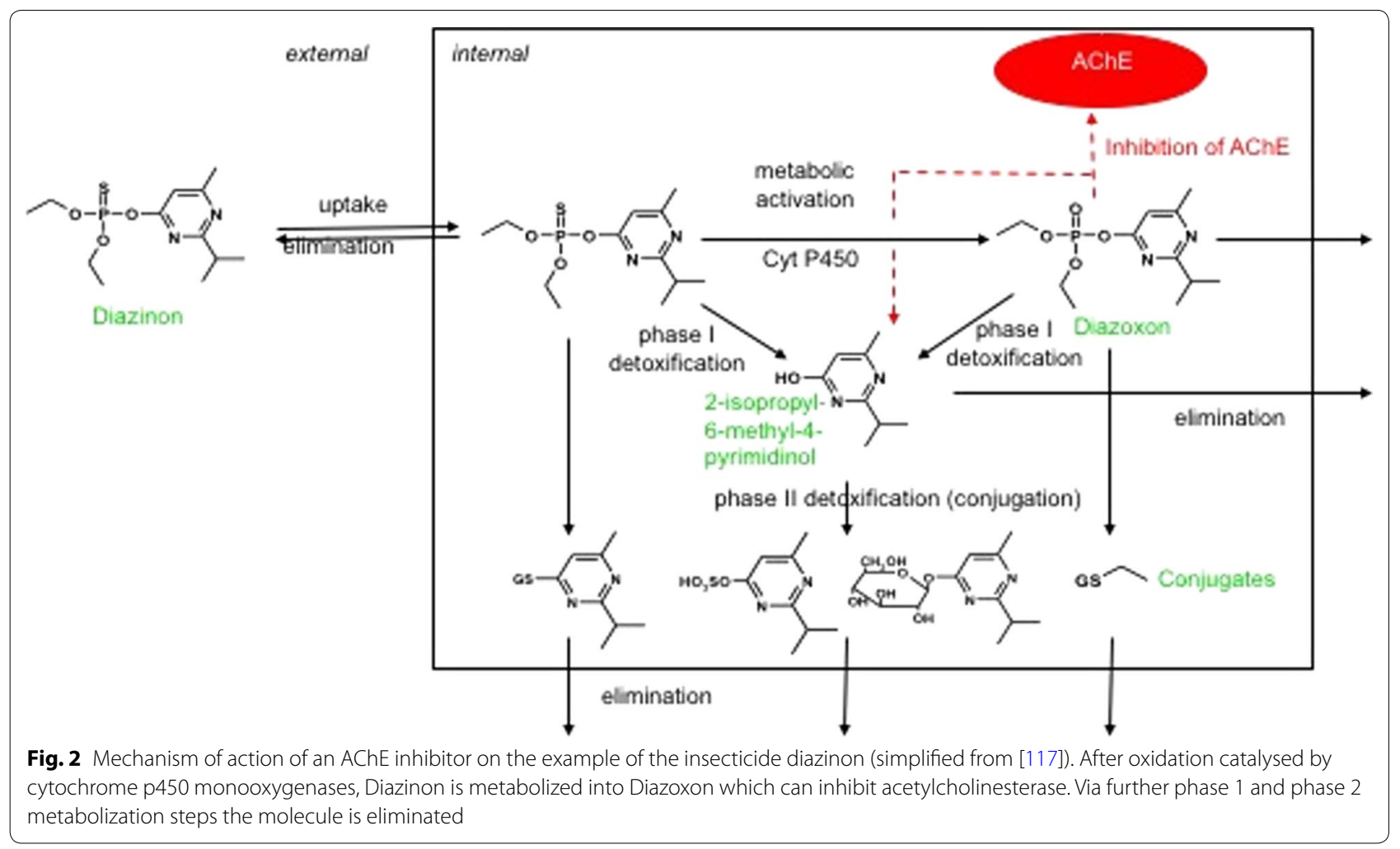


online biochemical detection after chromatography of potential AChE inhibitors [276].

\section{Cheminformatics approaches to assess eco-neurotoxicity}

While many argue that assessing neurotoxicity requires animal models, due to the sheer number and potential mixtures of chemicals as well as animal testing requirements, a shift to in vitro assays and computational toxicity approaches is required [278]. Fortunately, large quantities of chemical biological data have been released into the public domain over the past 10 years. This includes data that have resulted from the US federal governmentsponsored high-throughput screening programs such as Tox21 and ToxCast [279] testing thousands of chemicals against hundreds of assays (some of which are related to neurotoxicity). Furthermore, the development of online repositories such as ChEMBL [280] and PubChem [281] has resulted in collection and integration of chemogenomics data extracted from literature and/or directly deposited by researchers. Toxicological programs such as ToxCast $(>4000$ chemicals and $>1000$ high-throughput assays [282]) screening individual chemicals are extraordinarily resource intensive. Furthermore, as discussed above, a variety of neurotoxicity assays are needed to capture relevant endpoints [283]. Relevant neurotoxicity assays of varying sophistication and suitability for highthroughput studies include microelectrode arrays [128, $284]$, yeast assays [285, 286], assays using zebrafish [200, 287] and neural organoids derived from three-dimensional stem cell cultures [130].

In light of the chemical complexity in our environment, as discussed above, it is essential to connect predictive toxicity methods with the chemical signatures in samples to identify potential novel neurotoxicants in the environment before extensive neurotoxicity testing is performed. Computational toxicity approaches combined with literature-mining approaches and expert knowledge offer exciting ways to do this. Extensive work has already been performed by many research groups worldwide, screening drugs and potential neurotoxicants using various bioassays and collected into online resources such as ChEMBL and PubChem, including for instance the PubChem Classification Browser allowing sophisticated queries (e.g. results for Parkinson's disease [288, 289]. In particular, the U.S. EPA National Center for Computational Toxicology provides their data for download [290], including their in vitro data, and is incrementally releasing their data and computational models through the CompTox Dashboard [291]. This provides access to chemistry data, integrates to in vitro assay and exposure data, and links to external resources and literature-mining functionality [292]. The Dashboard has both prediction and generalized read-across models (GenRA) [293]. This resource therefore provides direct access to a suite of data and tools that can support neurotoxicity research as a hub for data and information for chemicals, including e.g. lists of known (human) neurotoxins [294]. Initiatives such as the Abstract Sifter provide users with an interactive Excel sheet to explore the occurrence of chemicals and endpoints in the literature [295]. One approach to connect these computational efforts to environmental observations includes incorporating neurotoxicity endpoints into "virtual fractionation" investigations (i.e. correlating environmental signals with toxicological effects in a statistical approach before performing extensive EDA), which is possible on both known and unknown signals [7]. Incorporating toxicological information during identification efforts in chemi$\mathrm{cal}$ analysis can help to prioritize signals of interest (as performed for mutagenicity, e.g. [296] and is now possible in the in silico identification approach MetFrag [297]. Extensions to MetFrag [298] to better integrate the computational toxicity information offered by the CompTox Dashboard, PubChem and other resources are underway. This will offer exciting new ways to prioritize candidates to improve non-target screening efforts [29] in all ecotoxicity contexts, including neurotoxicity. Connecting these efforts to big data approaches such as those implemented in GNPS [299] will offer novel data-mining opportunities in the years to come [300].

\section{The AOP concept in eco-neurotoxicity}

The adverse outcome pathway (AOP) framework is intended to structure evidence of mechanistic toxicity information for a more effective use in risk assessment and regulatory decision making [301]. An AOP is triggered by a molecular initiating event (MIE), which is the interaction of a compound with a molecular target such as a receptor, and further outlines the sequence of key events (KE) along different levels of biological organization from the molecular level up to the adverse outcome at a level of regulatory concern. The latter is generally the organismal level in human toxicology and the individual or population level in ecotoxicology. One of the earliest conceptual AOPs proposed concerned the neurotoxicity of domoic acid [302]. The OECD has taken on the task of coordinating international collaboration and harmonization of AOP development. The AOP-Wiki [303] aims at centralizing AOP descriptions into a publicly available repository to facilitate their application by the (eco)toxicologist community from industry, academia and regulatory institutions.

Two AOPs for neurotoxicity have been endorsed by the OECD, i.e. "Chronic binding of antagonists to $N$-methyl-D-aspartate receptors (NMDAR) during brain 
development inducing impairment of learning and memory abilities" [304] and "Binding of agonists to ionotropic glutamate receptors in adult brain causing excitotoxicity that mediates neuronal cell death, contributing to learning and memory impairment" [305, 307]. Four more neurotoxicity AOPs are currently either under review or approved (AOPs 10, 12, 42, 54). These describe binding to ionotropic GABA receptors leading to epileptic seizures [306], the role of NMDAR antagonists in neurodegeneration during ageing [307], and neurodevelopmental toxicity through interference with thyroid hormone synthesis (2 AOPs, [308]). For all of these AOPs, the focus is mostly on human health, although in some cases fruit fly, zebrafish or bobwhite quail data are included as weight of evidence. About 25 other AOPs currently being developed in the AOP-Wiki with a primary human toxicological perspective mainly focus on thyroid hormone disruption, and adrenergic, dopaminergic, serotonergic and opioid pathways.

AOPs covering neurotoxicity in an ecotoxicological context (about 25 in total in the AOP-Wiki) are at this point in time less advanced in general. Development of eco-neurotoxicity AOPs currently focuses on interference with cholinergic pathways leading to colony loss in bees and acute mortality in multiple species [309, 310], serotonergic (5-hydroxytryptamine transporter, 5-HTT) pathways leading to population changes in bivalves [311], and histamine, glutamate and GABA pathways, while some well-characterized pathways in mammals are currently lacking. Figure 4 shows an AOP network illustrating the current focus areas of eco-neurotoxicity AOP developers in the AOP-Wiki, as well as the interrelatedness of these research topics.
Currently, AOPs are mostly being developed separately for human toxicology and ecotoxicology, while many mechanisms are shared, especially among vertebrate taxa. The philosophy of modular AOP development facilitated by the AOP-Wiki, the evaluation of taxonomic applicability of AOPs and the concept of AOP networks [312], has the potential to aid in bridging the gap between these two fields. Figure 5 shows that although development of many human and eco-neurotoxicity AOPs are currently rather distinct processes, some connections between both fields are being established. The AOP of AChE leading to acute mortality provides a good example, since a specific effort has been made to make a broad assessment of taxonomic applicability based on species sensitivity distributions and sequence similarity assessment of the molecular target [310]. Other examples of studies that have attempted to broaden the taxonomic applicability domain of neurotoxicity AOPs include Gong et al. [306] for ionotropic GABA receptor antagonism and Fay et al. [311] who used Sequence Alignment to Predict Across Species Susceptibility (SeqAPASS, [313]) to assess conservation of the molecular target, in this case 5-HTT, across species.

\section{Molecular targets of environmental contaminants with neurotoxic/neuroactive mode of action}

AOPs for eco-neurotoxicity would support the development of bioassays for the detection of (converging) KEs that can be used to evaluate complex mixtures of chemicals triggering diverse neurotoxic AOPs. The recent AOPWiki (including putative AOPs) already reflects various targets and associated molecular initiating events that are known to lead to interference with the function and development of the nervous system (see previous section). Furthermore, many environmental contaminants

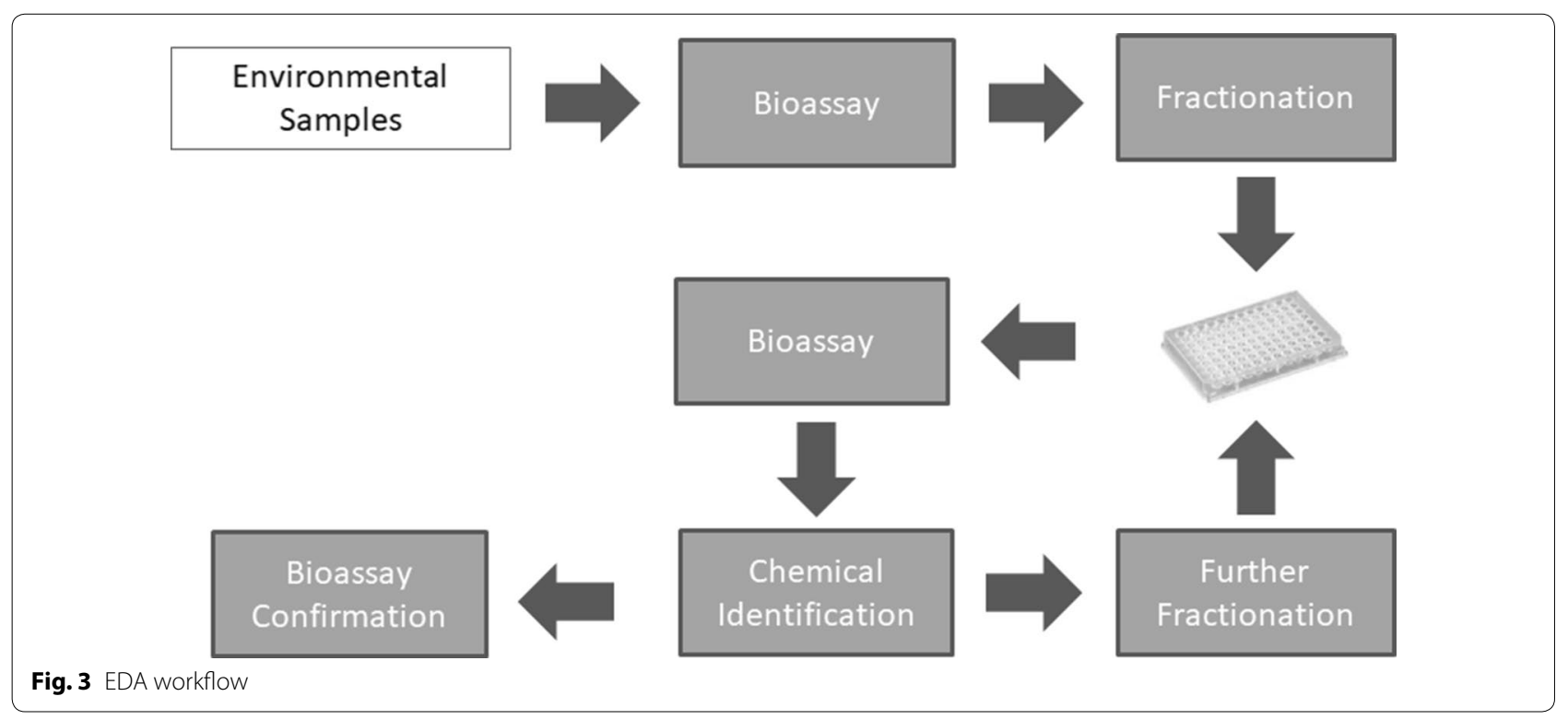


are known to interact with a biological target relevant for the function of the nervous system. This interaction can mostly be inferred from the intended biological effect in case of pharmaceuticals, pesticides and biocides. However, it remains to be demonstrated whether the intended biological target, such as the serotonin receptor, is also the MIE leading to a relevant adverse outcome and if other mechanisms of action than the reported pharmacological or insecticidal mechanism are leading to a neurotoxic/neuroactive effect as well. Compounds that have not been designed for biological activity (such as industrial chemicals) could also unintendedly impact on a target relevant for neuroactivity. Furthermore, available information on neuroactivity/neurotoxicity often stems from a specific animal class (e.g. mammals in case of pharmaceuticals) and it is not known whether the neuroactive mechanism also applies to other organisms.
An estimation of whether the recent AOP-Wiki captures some of the reported biological targets and associated AOPs of environmental contaminants (based on available information on neuroactivity) can be made by analysis of the mechanisms of action of contaminants frequently detected in the environment by large-scale analytical chemistry. By combining the data from studies that measured the concentration of several hundred different chemicals in three European river catchments (Danube, Rhine, Mulde/Saale), compounds with neurotoxicity/neuroactivity to any species were found as the largest group of chemicals with known MoA or target accounting for $13 \%$ of the 426 chemicals that were detected in at least one of the catchments [9].

By assigning a major molecular target to each of the neurotoxic/neuroactive chemicals in the study of Busch et al. using databases (DrugBank, IRAC) and

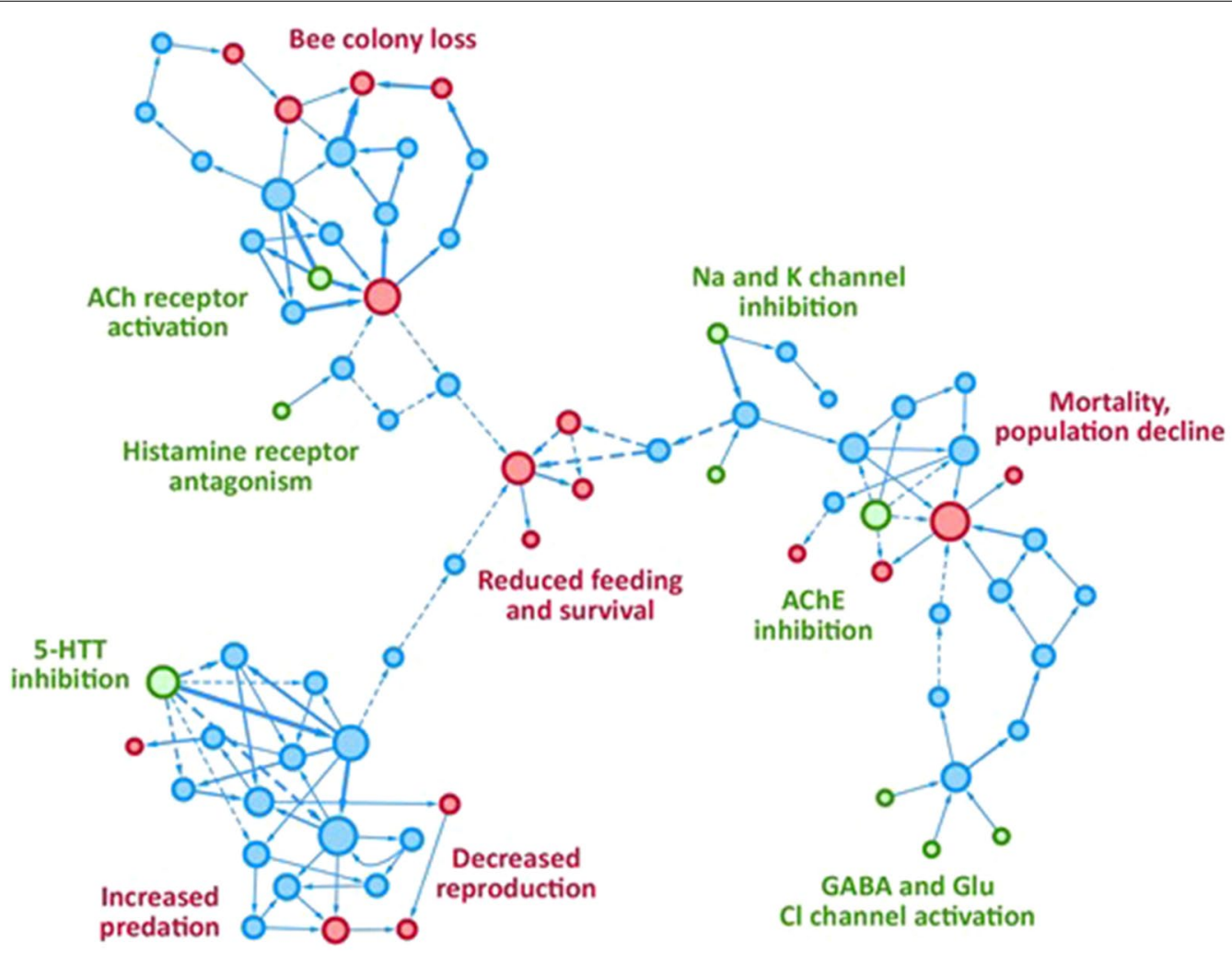

Fig. 4 AOP network showing all AOPs relevant to eco-neurotoxicity that are available in the AOP-Wiki (https://aopwiki.org; Accession date: April 30, 2018; AOP numbers 16, 77, 78, 79, 80, 82, 87, 88, 89, 90, 91, 93, 94, 95, 97, 98, 99, 113, 160, 161, 178, 195, 197, 203, 204; Network constructed using Cytoscape 3.6.1). Nodes in the network are key events (KEs), and edges represent key event relationships (KERs). Molecular initiating events are displayed in green, adverse outcomes in red. All other KEs are depicted in blue. Solid edges are adjacent KERs, dashed arrows are KERs that have been defined as non-adjacent (see the OECD's users' handbook for developing and assessing AOPs for more information, [333]). Node size represents node degree (the total number of KERs connecting the KE to the network, Villeneuve et al., and edge thickness represents the number of times a given KER is part of constituent AOPs in the network. While some of the AOPs in the network have been published, many are in early stages of development, and none have been reviewed or endorsed by the OECD. This figure and its annotations therefore merely illustrate the current focus areas of eco-neurotoxicity AOP developers in the AOP-Wiki, as well as the interrelatedness of these research topics. The AOP network does not make any inference about the scientific validity of the underlying AOPs, nor can it at this stage be used for in-depth biological interpretation or regulatory application. ACh, acetylcholine; AChE, acetylcholinesterase; 5-HTT, 5-hydroxytryptamine (serotonin) transporter; GABA, gamma-aminobutyric acid; Glu, glutamate; Na, sodium; K, potassium; Cl, chloride 


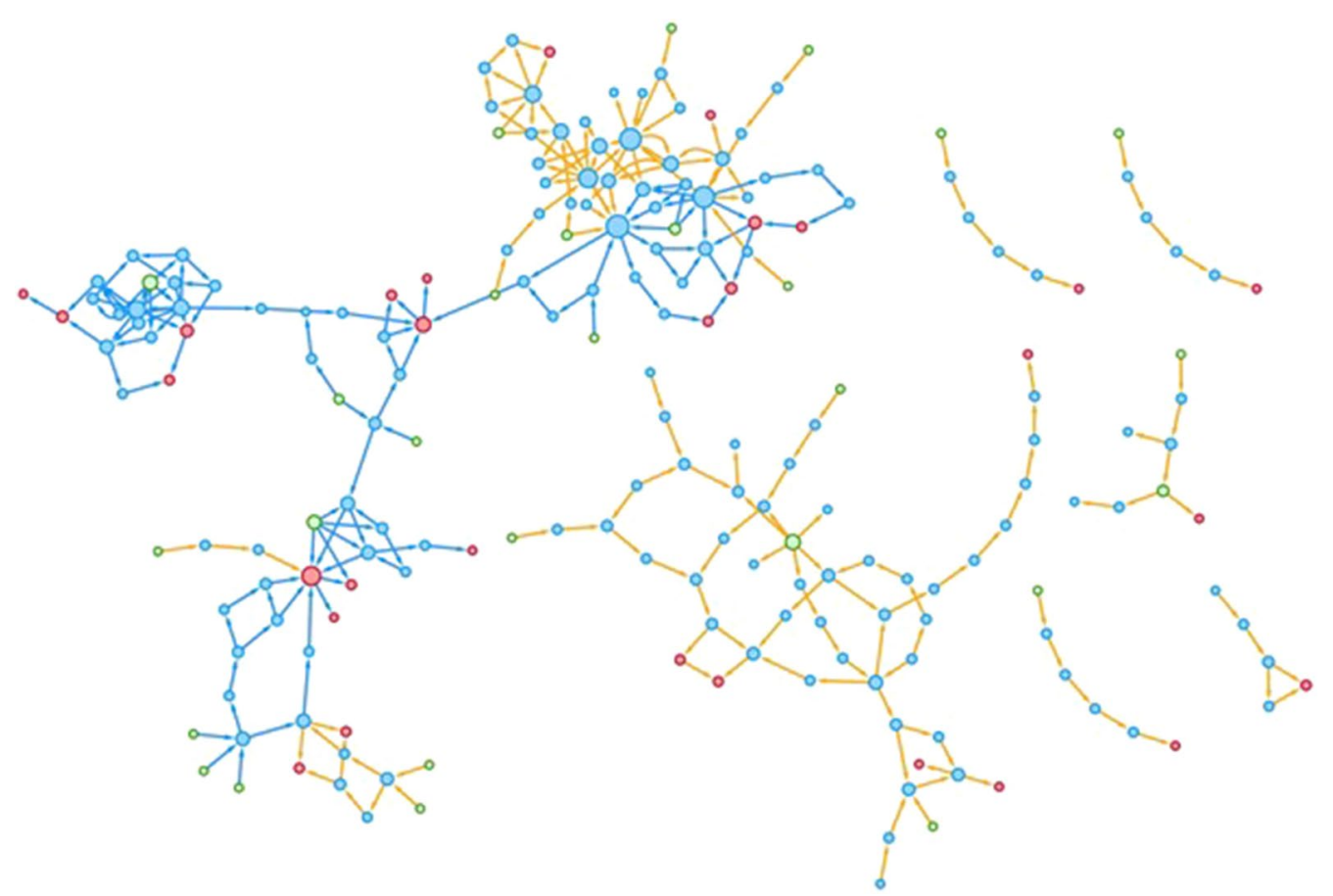

Fig. 5 Assembly of AOP networks showing all AOPs relevant to human (orange) and eco-neurotoxicity (blue) that are available in the AOP-Wiki (https://aopwiki.org; Accession date: April 30, 2018; Eco-neurotoxicity AOP numbers 16, 77, 78, 79, 80, 82, 87, 88, 89, 90, 91, 93, 94, 95, 97, 98, 99, $113,160,161,178,195,197,203,204$; Human neurotoxicity AOP numbers $3,8,10,12,13,17,26,42,48,54,73,104,112,126,134,152,164,170,214$, 215, 221, 222, 223, 224, 225, 226, 230, 231, 233, 234, 235, 236; Network constructed using Cytoscape 3.6.1). Nodes in the network are key events (KEs), and edges represent key event relationships (KERs). Molecular initiating events are displayed in green, adverse outcomes in red. All other KEs are depicted in blue. Node size represents node degree (the total number of KERs connecting the KE to the network, [334]). KERs in blue are part of eco-neurotoxicity AOPs and correspond to Fig. 4, KERs in orange are part of human neurotoxicity AOPs. The AOP network does not make any inference about the scientific validity of the underlying AOPs, nor can it at this stage be used for in-depth biological interpretation or regulatory application

public literature, 16 different mechanisms were identified (Table 2). Based on the hazard quotient (HQ), i.e. the ratio of observed concentrations and the measured or predicted effect concentrations for fish and daphnids, the different mechanisms of neuroactivity can be ranked with respect to their environmental relevance. Fifteen of those refer to a functional interference and only one represented a compound with developmental neurotoxicity (simazine, a herbicide with evidence to inhibit proliferation and differentiation of dopaminergic nerve cells [314]). This assignment could be partially biased since for some chemicals (i) the mechanism is not precisely known, (ii) other (neuroactive) mechanisms are reported as well and/or (iii) the data often stem from drug development or drug toxicity studies, and information whether the mechanism is applicable to environmental organisms is lacking. Nevertheless, the HQ assessment represents a useful approach to prioritize neurotoxicity AOPs that would be of major interest in ecotoxicology.

The HQ analysis using data from the study of Busch et al. [9] indicated that $\mathrm{AChE}$ inhibition is one of the most dominant MIEs, represented by 16 of the detected neurotoxic chemicals and displaying the highest HQs. These compounds are mainly pesticides but also include a few drugs such as rivastigmine used in the treatment of Alzheimer disease [315]. An elaborated AOP is available for fish toxicity [310] and assays that relate to the MIE (AChE enzyme activity, e.g. [316]) or key events (e.g. behaviour analysis in fish embryos relating to the KE of hyperactivity and paralysis, [231]) are available. AChE inhibitors are also well known for their relatively weak species specificity and they affect mammals and invertebrates as well. The highest HQs were found for invertebrates, which probably reflect the high sensitivity of invertebrates (AChE inhibitors have been mainly developed as insecticides). The ranking of AOPs for neuroactivity/neurotoxicity in ecotoxicity could be used to prioritize further development of AOPs by applying the following principles: (i) establishing AOPs for MIEs targeted by compounds with high $\mathrm{HQ}$, (ii) filling of data gaps to address species specificity, (iii) establishing new AOPs with focus on organisms and KE-related assays that 


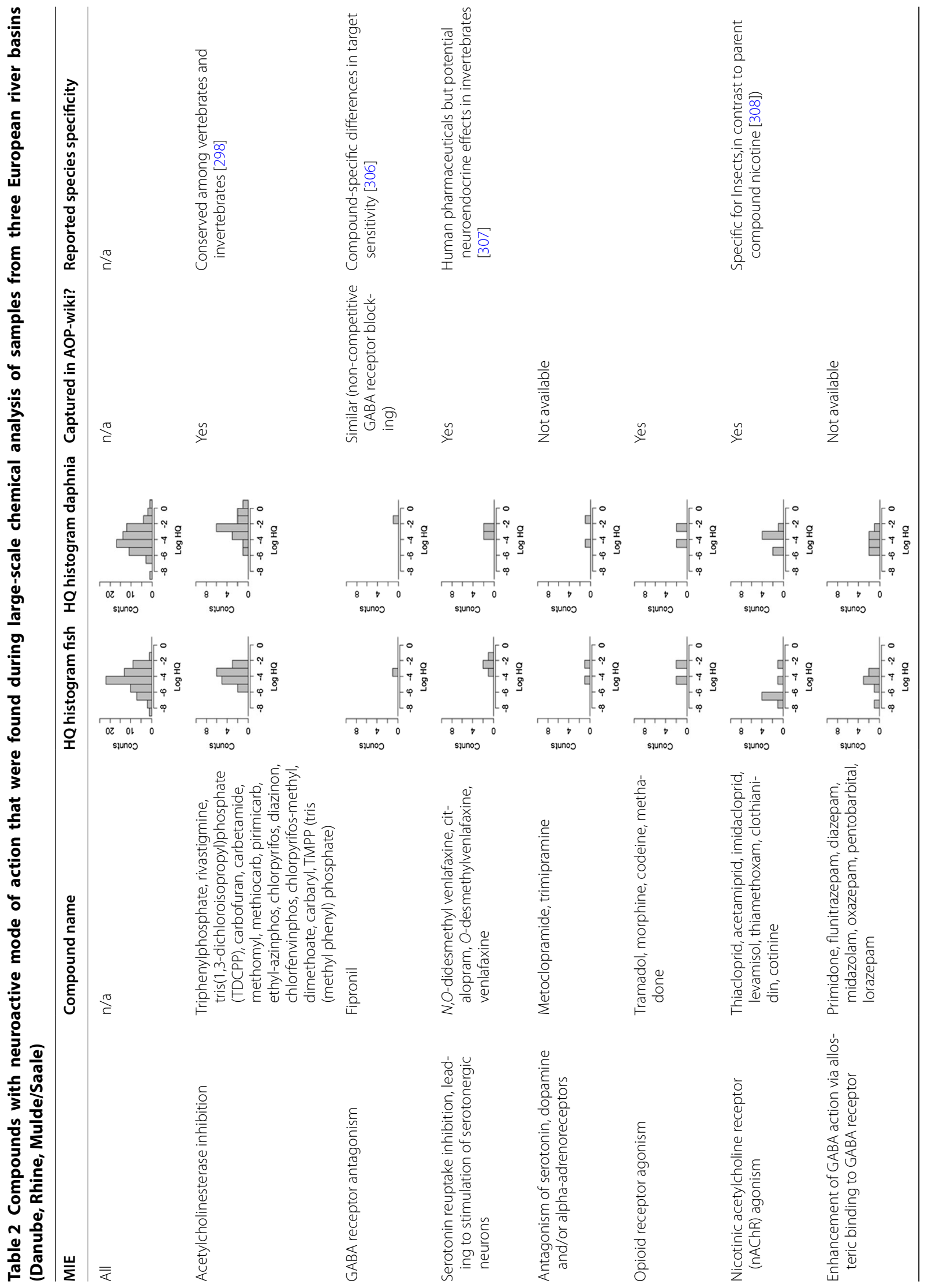




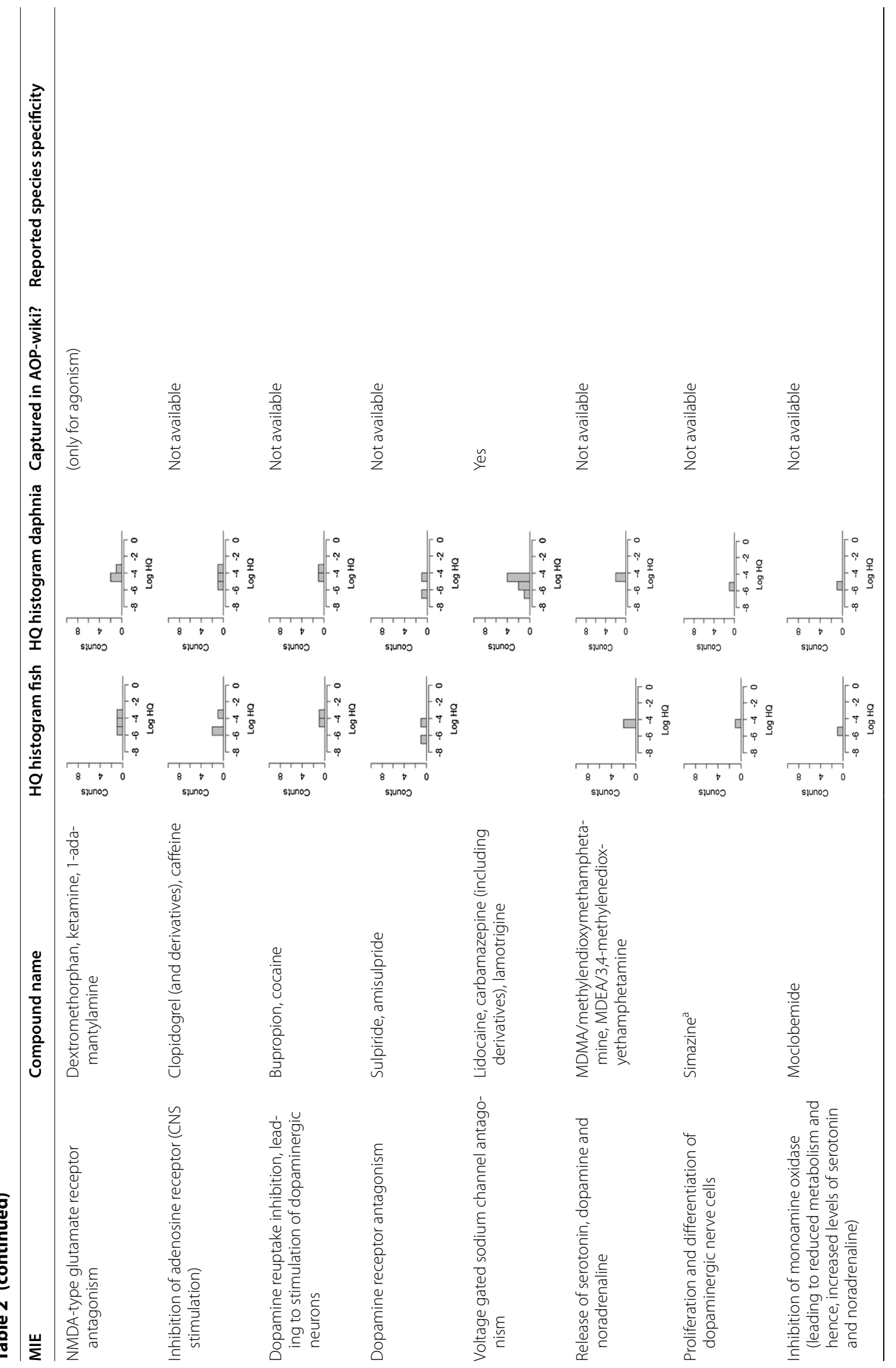




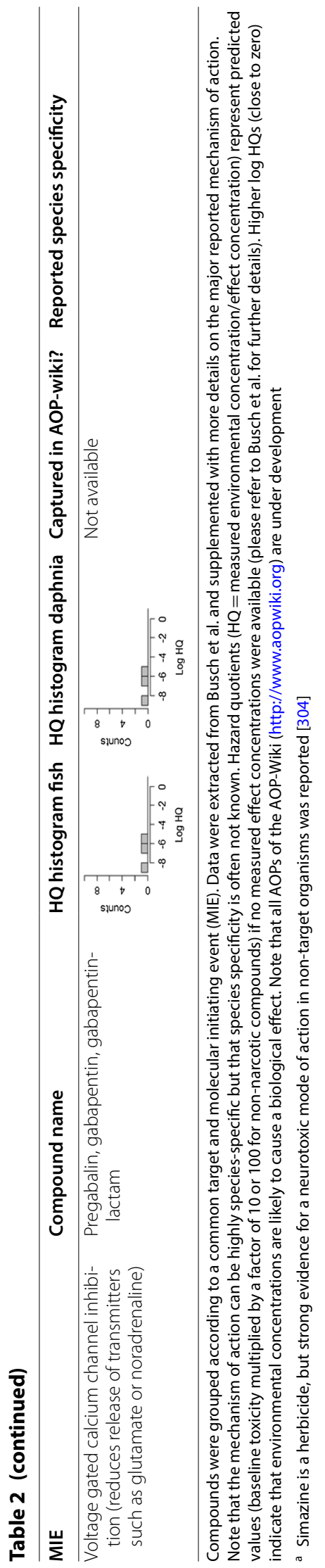


provide the opportunity to develop screening assays, and (iv) identification of converging KEs that could be used to develop bioassays that would allow to detect compounds targeting different AOPs. Identification of converging KEs would be useful in case of screening of compounds or the assessment of the cumulative impact of complex environmental mixtures using bioassays, given that otherwise large testing batteries to address different mechanisms would be required.

\section{Development of neurobehavior AOPs to predict population level impacts across species}

Behaviour assays can be powerful endpoints for contaminant experiments because behaviour integrates the internal physiological state of an animal with the animal's response to external stimuli at the same time [317] and can be a good indicator and measure of sublethal effects. Changes in behaviour can be incorporated into the AOP framework as whole organism responses, and it is useful to do so because of the potential utility of using AOPs for cross-species extrapolations and ecological risk assessment, and for using the fish embryo as a substitute for many traditional toxicity tests. Neurobehavioural impacts of contaminants have been documented in previous laboratory [318, 319] and/or field [320] studies involving fish.

Embedding behaviour into an AOP that predicts ecologically relevant adverse outcome is challenging because it is difficult to interpret subtle changes in behaviour in terms of population demographics. There have been some development in methods to link behavioural outcomes to population relevant impacts that are suitable for ecological risk assessment [321-324]. As fish larvae are particularly sensitive to predation and starvation, impaired behaviour related to foraging and predator avoidance may have drastic consequences to the individual [325]. Ecologically relevant behaviours that should be measured in contaminant-exposed fish include swimming speed, startle response, reactive distances, prey capture ability, learning and memory. These behaviours can be related to the probability of escaping a predator, capturing prey for feeding and encounter rates using statistical models. Some examples of directed laboratory studies that were used to focus on behaviour relevant to ecological processes such as foraging and predator avoidance and subsequently used to construct an individual based model calibrated for particular species and populations are available [323, 324].

With behaviour as a pivot key event in the development of an AOP, there are challenges associated with incorporating suborganismal information. Prior to the onset of clinically apparent neurobehavioural damage, significant changes in brain neurochemistry occur and monitoring such changes using neurochemical biomarkers or key events represents an objective and early means to identify key molecular initiating events. The associations between measurable disruptions in brain gene expression measured using RNAseq, metabolomics and reverse engineering, and probabilities of capturing prey and avoiding predators can then be incorporated into a larval fish cohort model (e.g. [321, 322, 324, 326]), to predict survival and growth of the cohort. Cohort survival and growth can also be easily translated into parameters relevant to common metrics used by regulatory agencies (e.g. EC50; [322]), and can also be incorporated into a matrix population model to predict population effects of contaminant via induced changes in behaviour [327]. However, more work is needed to use valuable behavioural assays to create powerful AOPs that link the effects of chemicals from the level of molecular initiation all the way to the population.

The AOP framework has been proposed to be suitable for cross-species extrapolations [328]; however, for neurobehavioural studies, there are distinct challenges that will have to be addressed. Right now, in ecological risk assessment just a few selected species that are easy to maintain in the laboratory are used to make decisions on over 32,500 species of fish [328]. Test species are rarely selected for geographical range, physiology or life history. However, as baseline behaviour can vary widely between species, and as it is challenging to get non-laboratory model organisms to behave normally in laboratory settings, applying the neurobehavioural response as a key event to indicate population outcomes can be difficult for many species [326]. To perform cross-species extrapolations, the AOP framework can be used to identify key events that are more informative and easier to measure. For example, it may be possible to develop a neurobehavioural AOP in a model species like the zebrafish and extrapolate to other species of ecological importance. A neurobehavior AOP that targets larval life stages (a stage that is easy to maintain and test in the laboratory) would be ideal for cross-species extrapolations and would be in direct concordance with the spirit of the NRC 2007 report "Toxicity Testing in the 21st Century: A Vision and a Strategy" [329]. To use the zebrafish or another model species to predict neurobehavior adverse outcomes in another species, the same information should be collected at every level of biological organization across multiple KEs to determine what information is useful for cross-species comparisons, what information is lost by using a model species and the errors associated with cross-species assumptions [326, 330]. Essentially, there may be KEs that can be measured at the suborganism level that are better at predicting population outcomes than neurobehavioural KEs. Once a few crossspecies comparisons have been completed using the AOP 
framework in a systematic way, the neurobehavioural KE may be replaced with a molecular or cellular KE and used to make population predictions for alternate species instead. These molecular/cellular KEs are likely to be more amenable to high-throughput methods than behavioural responses.

\section{Conclusions}

\section{Current situation}

Considering the increasing numbers of environmental contaminants, their unknown neurotoxic potential, the physiological and morphological complexity of the nervous system, and the wide range of potential consequences of neurotoxicity, it is a major challenge to identify and advance neurotoxicity testing strategies and methods that improve neurotoxicity and eco-neurotoxicity assessment [331]. Additionally, neurotoxicity end especially eco-neurotoxicity is a challenging endpoint. Developmental processes, hormones, epigenetic regulations, the microbiome and many other processes can all impact nervous system functioning. Toxic MoA can be rather simplistic like AChE inhibition, but even then, differences in species sensitivities can make it rather difficult to assess eco-neurotoxicity.

\section{Recommendations}

\section{Effects}

Many different compounds such as flame retardants, plasticizers, pesticides and pharmaceuticals are suspected to be neurotoxic based on epidemiological studies in humans and eco-neurotoxic based on environmental species. Neurotoxic effects can be seen after exposure to trace levels of micropollutants. There is only very limited information available when it comes to eco-neurotoxic effects but based on what is known we propose that:

- Neurotoxicity studies should include the sensitive stages of development for the selected test species. Additional testing for developmental effects, including long-term effects, with, e.g. zebrafish, medaka, bird eggs, should be performed.

- Epigenetic effects should be investigated. Epigenetic effects can indicate multi-generation effects, which are especially relevant when looking at whole ecosystems.

- The biomolecular process like transcriptomic or metabolomic changes and their link to behavioural alterations should be investigated in more detail.

- Due to the close link between the hormonal system and the nervous system, endocrine effects should be tested for potential neurotoxic effects.
- Most known neurotoxic MoA describes interference with synapse functioning like binding to neurotransmitter receptors or effects on calcium homeostasis. Species-specific differences in sensitivity are often due to differences in the detoxification metabolism. This should be taken under consideration when selecting species or assays. To compensate for this, pre-metabolization steps could be included or metabolites tested as well as parent compounds.

- The application of TK-TD models might be helpful to better understand the impact of different exposure scenarios.

- Mixture assessments for solely neurotoxic substances but also in combination with non-neurotoxic substances are needed.

\section{Chemistry}

The number of compounds in daily use and consequently emitted in the environment is increasing and monitoring all of them in the environment is challenging, especially in biota. Potential solutions are to

- Identify potential unknown neurotoxicants within an environment using effect-based monitoring that can be combined with effect-directed analysis. Reliable, high-throughput assays are needed to enable this approach.

- Use cheminformatics approaches or toxic pressure modelling to incorporate computational toxicological information with chemical (monitoring) data.

\section{Assays}

Current in vivo test systems are mostly developed for human neurotoxicity assessment, although they could be easily adapted for ecological use. The current systems mostly do not allow large-scale screening. To be able to screen all relevant environmental contaminants for their neurotoxic potential, novel screening approaches are needed.

These assays should be:

- Applicable for high-throughput, cost-efficient and alternatives to animal testing.

- Due to the complexity of the nervous system, only a test battery of in vitro assays covering different MoAs will be able to replace current whole animal tests. To develop such a battery, it is necessary to understand the involved mechanisms of toxicity and to establish causal relationships between neurotoxicity endpoints and behavioural consequences [332]. AOPs might help in selecting targets. 
- Developing a set of test chemicals, covering different MoAs might be useful for assay validation studies.

\section{Risk assessment}

In Europe, neurotoxicity of compounds is only assessed for human exposure thus far, and only for medium and high production volume chemicals, not based on exposure levels. Effects on organisms in the environment are not considered.

- Online-biomonitoring systems for measuring behaviour of sensitive organisms within an ecosystem could be used as early warning systems.

- EDA and Toxic Pressure modelling could be used to identify hazardous substances.

- To include eco-neurotoxicity assessment, cheminformatics in combination with in vitro screening tests could be used as first tier to screen compounds found in an ecosystem for neurotoxicity. AOPs can be helpful in guiding this process. In vitro assays for relevant mechanisms of neurotoxicity could then be implemented, validated and combined in a test battery. For eco-neurotoxicity assessment, species differences should be considered in the selection of in vitro assays.

- In a second tier, a test battery using small species covering different trophic levels could be used to assess risks of ecosystems. Such testing batteries could be also applied for mixture assessment and in combination with effect-directed analysis to identify neurotoxic pollutants in the environment.

There is a clear need to better understand how compounds can cause eco-neurotoxicity and how this differs between species. Only when the most sensitive species is protected, harm to the environment can be prevented. Novel methods or strategies need to be developed, able to deal with the large amounts of environmental pollutants, the complexity of the nervous system and the diversity of the ecosystem. Such methods will allow to implement eco-neurotoxicity as part of EU legislation.

\footnotetext{
Abbreviations

AA-EQS: annual average environmental quality standards; AAS: atomic absorption spectroscopy; AChE: acetylcholinesterase; AOP: adverse outcome pathway; CNS: central nervous system; DNMT: DNA methyltransferase; DNT: developmental neurotoxicity; ECHA: European Chemicals Agency; EDA: effect-directed analysis; EDC: endocrine disrupting chemical; EFSA: European Food Safety Agency; ELS: early life stage; ESI: electrospray ionization; FET: fish embryotoxicity test; GABA: g-aminobutyric acid; GC-MS: gas chromatography coupled to mass spectrometry; GenRA: generalized read-across models; HQ: hazard quotient; HRIV: health-related indicator value; HRMS: high-resolution mass analyser; ICP-MS: inductively couples plasma mass spectrometry; KE: key event; LC-MS: liquid chromatography coupled to mass spectrometry;
}

MAC-EQS: maximum allowable environmental quality standards; MEA: multielectrode array; MIE: molecular initiating event; MoA: mode of action; MRM: multiple reaction monitoring; msPAF: multiple-substances potentially affected fraction; NMDAR: N-methyl-D-aspartate receptors; PAF: potentially affected fraction; REACH: registration, evaluation, authorisation and restriction of chemicals; SIMONI: smart Integrated monitoring; TEl: transgenerational epigenetic inheritance; TK-TD: toxicokinetic-toxicodynamic; TOF: time-of-flight; WFD: Water Framework Directive.

\section{Authors' contributions}

$J \mathrm{~L}, \mathrm{CDP}$ and $\mathrm{HH}$ conceptualized the manuscript. $J \mathrm{~L}$ and CDP edited the manuscript and coordinated the contributions. MHSK, HGvanderG, ELS, AJW, MMLD RM, WB, XC, M-LB, RvanderO, AC, VS-U, FS, BIE, ME, GN, SHK, DP, PW, CK, IW, A-CH, DK, LV, MS, WS, WB, DL, SS, CvomB, NB, CM, JK, TG and HH contributed specific aspects to the manuscript and improved the manuscript content. All authors read and approved the final manuscript.

\section{Author details}

${ }^{1}$ Institute for Environmental Research, Department of Ecosystem Analysis, ABBt-Aachen Biology and Biotechnology, RWTH Aachen University, Worringerweg 1, 52074 Aachen, Germany. ${ }^{2}$ Environment and Health, VU University, 1081 HV Amsterdam, The Netherlands. ${ }^{3}$ FAME-Freshwater and Marine Ecology, Institute for Biodiversity and Ecosystem Dynamics, University of Amsterdam, P.O. Box 94248, 1090 GE Amsterdam, The Netherlands. ${ }^{4}$ Luxembourg Centre for Systems Biomedicine (LCSB), University of Luxembourg, 6 Avenue du Swing, 4367 Belvaux, Luxembourg. ${ }^{5}$ National Center for Computational Toxicology, Office of Research and Development, U.S. Environmental Protection Agency, 109 T.W. Alexander Dr., Research Triangle Park, NC 27711, USA. ${ }^{6}$ KWR Watercycle Research Institute, Groningenhaven 7, 3433 PE Nieuwegein, The Netherlands. ${ }^{7}$ Department Effect-Directed Analysis, Helmholtz Centre for Environmental Research-UFZ, Permoserstr. 15, Leipzig, Germany. ${ }^{8}$ Ifremer, UMR MARBEC, Laboratoire Adaptation et Adaptabilités des Animaux et des Systèmes, Route de Maguelone, 34250 Palavas-les-Flots, France. ${ }^{9}$ INRA, UMR GABI, INRA, AgroParisTech, Domaine de Vilvert, Batiment 231, 78350 Jouy-en-Josas, France. ${ }^{10}$ Ifremer, Laboratoire Ressources Halieutiques, Place Gaby Coll, 17137 L'Houmeau, France. ${ }^{11}$ Department of Technology, Research and Engineering, Waternet Institute for the Urban Water Cycle, Amsterdam, The Netherlands. ${ }^{12}$ Laboratory of Evolutionary and Adaptive Physiology, Institute of Life, Earth and Environment, University of Namur, 5000 Namur, Belgium. ${ }^{13}$ Department of Cell Toxicology, Helmholtz Centre for Environmental Research-UFZ, Permoserstr. 15, 04318 Leipzig, Germany. ${ }^{14}$ Eberhard Karls University Tübingen, Environmental Toxicology, Center for Applied Geosciences, 72074 Tübingen, Germany. ${ }^{15}$ MTM Research Centre, School of Science and Technology, Örebro University, Fakultetsgatan 1, 70182 Örebro, Sweden. ${ }^{16}$ Faculty of Chemical Engineering and Biotechnology, University of Applied Sciences Darmstadt, Stephanstrasse 7, 64295 Darmstadt, Germany. ${ }^{17}$ Swiss Centre for Applied Ecotoxicology Eawag-EPFL, Überlandstrasse 133, 8600 Dübendorf, Switzerland. ${ }^{18}$ Zebrafishlab, Veterinary Physiology and Biochemistry, University of Antwerp, Wilrijk, Belgium. ${ }^{19}$ Institute for Biology II, Department of Chemosensation, RWTH Aachen University, Aachen, Germany. ${ }^{20}$ Zweckverband Landeswasserversorgung, Langenau, Germany. ${ }^{21}$ Department of Bioanalytical Ecotoxicology, UFZ-Helmholtz Centre for Environmental Research, Leipzig, Germany. ${ }^{22}$ Department of Environmental Toxicology, Swiss Federal Institute of Aquatic Science and Technology, Eawag, Dübendorf 8600, Switzerland. ${ }^{23}$ Faculty of Agricultural and Environmental Sciences, McGill University, Montreal, Canada. ${ }^{24}$ Department of Fisheries and Wildlife, Michigan State University, East Lansing, USA. ${ }^{25}$ Institute of Physiology (Neurophysiology), Aachen, Germany. ${ }^{26}$ Section Toxicology of Drinking Water and Swimming Pool Water, Federal Environment Agency (UBA), Heinrich-Heine-Str. 12, 08645 Bad Elster, Germany.

\section{Acknowledgements}

We thank the Federal Ministry of Education and Research (BMBF) founded project NeuroBox and the Norman Network (http://www.norman-netwo rk.com/) for funding this study. Additionally, this work was conducted within the framework of the Joint Research Program of the Dutch Water companies (BTO2018-2023) and the SOLUTIONS project (European Union's Seventh Framework Program for research, technological development and demonstration under Grant Agreement No. 603437). Henner Hollert is Editor-in-Chief of this Journal. 


\section{Competing interests}

The authors declare that they have no competing interests.

\section{Availability of data and materials}

Not applicable; presented information is based on previously published data only.

\section{Consent for publication}

Not applicable.

\section{E.P.A. disclaimer}

The views expressed in this paper are those of the authors and do not necessarily represent the views or policies of the U.S. Environmental Protection Agency.

\section{Ethics approval and consent to participate}

Not applicable.

\section{Publisher's Note}

Springer Nature remains neutral with regard to jurisdictional claims in published maps and institutional affiliations.

Received: 18 September 2018 Accepted: 31 October 2018

Published online: 14 December 2018

\section{References}

1. Hellou J (2011) Behavioural ecotoxicology, an "early warning" signal to assess environmental quality. Environ Sci Pollut Res Int 18:1-11

2. Scott GR, Sloman KA (2004) The effects of environmental pollutants on complex fish behaviour: integrating behavioural and physiological indicators of toxicity. Aquat Toxicol 68:369-392

3. Basu N (2012) Piscivorous mammalian wildlife as sentinels of methylmercury exposure and neurotoxicity in humans. In: Ceccatelli S, Aschner M (eds) Methylmercury and neurotoxicity. Springer, Boston, pp 357-370

4. Basu N, Head J (2010) Mammalian wildlife as complementary models in environmental neurotoxicology. Neurotoxicol Teratol 32:114-119

5. Valinluck V, Tsai H-H, Rogstad DK, Burdzy A, Bird A, Sowers LC (2004) Oxidative damage to methyl-CpG sequences inhibits the binding of the methyl-CpG binding domain (MBD) of methyl-CpG binding protein 2 (MeCP2). Nucleic Acids Res 32:4100-4108

6. Wright RO, Baccarelli A (2007) Metals and neurotoxicology. J Nutr 137:2809-2813

7. Brack W, Ait-Aissa S, Burgess RM, Busch W, Creusot N, Di Paolo C et al (2016) Effect-directed analysis supporting monitoring of aquatic environments - an in-depth overview. Sci Total Environ 544:1073-1118

8. Tilson HA, MacPhail RC, Crofton KM (1995) Defining neurotoxicity in a decision-making context. Neurotoxicology 16:363-375

9. Busch W, Schmidt S, Kühne R, Schulze T, Krauss M, Altenburger R (2016) Micropollutants in European rivers: a mode of action survey to support the development of effect-based tools for water monitoring. Environ Toxicol Chem 35:1887-1899

10. National Research Council (US) (2014) Committee on neurotoxicology and models for assessing risk. Environmental neurotoxicology. National Academies Press (US), Washington (DC)

11. Westerink RHS (2013) Do we really want to REACH out to in vitro? Neurotoxicology 39:169-172

12. for Economic Co-operation O, Development. Test No. 424: Neurotoxicity Study in Rodents. OECD Publishing; 1997

13. for Economic Co-operation O, Development. Test No. 418: Delayed neurotoxicity of organophosphorus substances following acute exposure. OECD Publishing; 1995

14. for Economic Co-operation O, Development. Test No. 419: Delayed neurotoxicity of organophosphorus substances: 28-day repeated dose study. OECD Publishing; 1995

15. for Economic Co-operation O, Development. Test No. 426: Developmental neurotoxicity study. OECD Publishing; 2007
16. Forum USEPARA. Guidelines for neurotoxicity risk assessment. Risk Assessment Forum, US Environmental Protection Agency; 1998

17. Sastre S, Fernández Torija C, Atiénzar Pertusa I, Beltrán EM, Pablos MV, González-Doncel M (2018) Stage-dependent effects of chlorpyrifos on medaka (Oryzias latipes) swimming behavior using a miniaturized swim flume. Aquat Toxicol 200:37-49

18. de Melo Tarouco F, de Godoi FGA, Velasques RR, da Silveira Guerreiro A, Geihs MA, da Rosa CE (2017) Effects of the herbicide Roundup on the polychaeta Laeonereis acuta: cholinesterases and oxidative stress. Ecotoxicol Environ Saf 135:259-266

19. Larsen KE, Lifschitz AL, Lanusse CE, Virkel GL (2016) The herbicide glyphosate is a weak inhibitor of acetylcholinesterase in rats. Environ Toxicol Pharmacol 45:41-44

20. Oliveira C, Almeida JR, Guilhermino L, Soares AMVM, Gravato C (2013) Swimming velocity, avoidance behavior and biomarkers in Palaemon serratus exposed to fenitrothion. Chemosphere 90:936-944

21. Almeida JR, Oliveira C, Gravato C, Guilhermino L (2010) Linking behavioural alterations with biomarkers responses in the European seabass Dicentrarchus labrax L. exposed to the organophosphate pesticide fenitrothion. Ecotoxicology 19:1369-1381

22. Walker CH (2003) Neurotoxic pesticides and behavioural effects upon birds. Ecotoxicology 12:307-316

23. Masjosthusmann S, Barenys M, El-Gamal M, Geerts L, Gerosa L, Gorreja A et al (2018) Literature review and appraisal on alternative neurotoxicity testing methods. EFSA Support Publ 15:1410E

24. European Commission. Directive of the European Parliament and of the Council amending Directives 2000/60/EC and 2008/105/EC as regards priority substances in the field of water policy. 2012

25. Escher B, Leusch F (2011) Bioanalytical tools in water quality assessment. IWA Publishing, London

26. Silva E, Rajapakse N, Kortenkamp A (2002) Something from "nothing"eight weak estrogenic chemicals combined at concentrations below NOECs produce significant mixture effects. Environ Sci Technol 36:1751-1756

27. Escher BI, Fenner K (2011) Recent advances in environmental risk assessment of transformation products. Environ Sci Technol 45:3835-3847

28. van der Oost R, Beyer J, Vermeulen NPE (2003) Fish bioaccumulation and biomarkers in environmental risk assessment: a review. Environ Toxicol Pharmacol 13:57-149

29. Hollender J, Schymanski EL, Singer HP, Ferguson PL (2017) Nontarget screening with high resolution mass spectrometry in the environment: ready to go? Environ Sci Technol 51:11505-11512

30. TrinkwV (2001) "Trinkwasserverordnung in der Fassung der Bekanntmachung vom 10. März 2016 (BGBI. I S. 459), die zuletzt durch Artikel 1 der Verordnung vom 3. January 2018 (BGBI. I S. 99) geändert worden ist. BoD-Books on Demand; 2018

31. Appleton AA, Jackson BP, Karagas M, Marsit CJ (2017) Prenatal exposure to neurotoxic metals is associated with increased placental glucocorticoid receptor DNA methylation. Epigenetics. 12:607-615

32. Grummt T, Kuckelkorn J et al (2013) Tox-Box: securing drops of life-an enhanced health-related approach for risk assessment of drinking water in Germany. Environ Sci Europe. 25:27

33. Rice D, Barone S Jr (2000) Critical periods of vulnerability for the developing nervous system: evidence from humans and animal models. Environ Health Perspect 108(Suppl 3):511-533

34. Grandjean P, Landrigan PJ (2006) Developmental neurotoxicity of industrial chemicals. Lancet 368:2167-2178

35. Makris SL, Raffaele K, Allen S, Bowers WJ, Hass U, Alleva E et al (2009) A retrospective performance assessment of the developmental neurotoxicity study in support of OECD test guideline 426. Environ Health Perspect 117:17-25

36. Crofton KM, Mundy WR, Shafer TJ (2012) Developmental neurotoxicity testing: a path forward. Congenit Anom. 52:140-146

37. Fritsche E, Grandjean P, Crofton KM, Aschner M, Goldberg A, Heinonen T et al (2018) Consensus statement on the need for innovation, transition and implementation of developmental neurotoxicity (DNT) testing for regulatory purposes. Toxicol Appl Pharmacol. https://doi.org/10.1016/j. taap.2018.02.004

38. Basu N (2015) Applications and implications of neurochemical biomarkers in environmental toxicology. Environ Toxicol Chem 34:22-29 
39. Padilla S, Cowden J, Hinton DE, Yuen B, Law S, Kullman SW et al (2009) Use of medaka in toxicity testing. Curr Protoc Toxicol. 1:10

40. Ton C, Lin Y, Willett C (2006) Zebrafish as a model for developmental neurotoxicity testing. Birth Defects Res A Clin Mol Teratol. 76:553-567

41. Nishimura Y, Murakami S, Ashikawa Y, Sasagawa S, Umemoto N, Shimada Y et al (2015) Zebrafish as a systems toxicology model for developmental neurotoxicity testing. Congenit Anom. 55:1-16

42. Buznikov GA, Nikitina LA, Bezuglov VV, Lauder JM, Padilla S, Slotkin TA (2001) An invertebrate model of the developmental neurotoxicity of insecticides: effects of chlorpyrifos and dieldrin in sea urchin embryos and larvae. Environ Health Perspect 109:651-661

43. Buznikov GA, Nikitina LA, Rakić LM, Milošević I, Bezuglov WV, Lauder JM et al (2007) The sea urchin embryo, an invertebrate model for mammalian developmental neurotoxicity, reveals multiple neurotransmitter mechanisms for effects of chlorpyrifos: therapeutic interventions and a comparison with the monoamine depleter, reserpine. Brain Res Bull 74:221-231

44. Hicks C, Sorocco D, Levin M (2006) Automated analysis of behavior: a computer-controlled system for drug screening and the investigation of learning. J Neurobiol 66:977-990

45. Leung MCK, Williams PL, Benedetto A, Au C, Helmcke KJ, Aschner M et al (2008) Caenorhabditis elegans: an emerging model in biomedical and environmental toxicology. Toxicol Sci 106:5-28

46. Bradley M, Rutkiewicz J, Mittal K, Fernie K, Basu N (2015) In ovo exposure to organophosphorous flame retardants: survival, development, neurochemical, and behavioral changes in white leghorn chickens. Neurotoxicol Teratol 52:228-235

47. Rutkiewicz J, Bradley M, Mittal K, Basu N (2013) Methylmercury egg injections: part 2-pathology, neurochemistry, and behavior in the avian embryo and hatchling. Ecotoxicol Environ Saf 93:77-86

48. Escher BI, Hermens JLM (2002) Modes of action in ecotoxicology: their role in body burdens, species sensitivity, QSARs, and mixture effects. Environ Sci Technol 36:4201-4217

49. Ashauer R, Jager $T$ (2018) Physiological modes of action across species and toxicants: the key to predictive ecotoxicology. Environ Sci Process Impacts. 20:48-57

50. Jablonka E, Lamb MJ (2002) The changing concept of epigenetics. Ann NY Acad Sci 981:82-96

51. Bollati V, Baccarelli A (2010) Environmental epigenetics. Heredity 105:105-112

52. Perera F, Herbstman J (2011) Prenatal environmental exposures, epigenetics, and disease. Reprod Toxicol 31:363-373

53. Guerrero-Bosagna C, Settles M, Lucker B, Skinner MK (2010) Epigenetic transgenerational actions of vinclozolin on promoter regions of the sperm epigenome. PLoS ONE. https://doi.org/10.1371/journ al.pone. 0013100

54. Hemberger M, Dean W, Reik W (2009) Epigenetic dynamics of stem cells and cell lineage commitment: digging Waddington's canal. Nat Rev Mol Cell Biol 10:526-537

55. Li E (2002) Chromatin modification and epigenetic reprogramming in mammalian development. Nat Rev Genet 3:662-673

56. Reik W, Dean W, Walter J (2001) Epigenetic reprogramming in mammalian development. Science 293:1089-1093

57. Feng S, Jacobsen SE, Reik W (2010) Epigenetic reprogramming in plant and animal development. Science 330:622-627

58. Potok ME, Nix DA, Parnell TJ, Cairns BR (2013) Reprogramming the maternal zebrafish genome after fertilization to match the paternal methylation pattern. Cell 153:759-772

59. Fellous A, Earley R, Silvestre F (2018) DNA methylation in adults and during development of the self-fertilizing mangrove rivulus, Kryptolebias marmoratus. Ecol Evol 8:6016

60. Banik A, Kandilya D, Ramya S, Stünkel W, Chong YS, Dheen ST (2017) Maternal factors that induce epigenetic changes contribute to neurological disorders in offspring. Genes. https://doi.org/10.3390/genes 8060150

61. Feng J, Fouse S, Fan G (2007) Epigenetic regulation of neural gene expression and neuronal function. Pediatr Res 61:58R-63R

62. Raciti M, Ceccatelli S (2018) Epigenetic mechanisms in developmental neurotoxicity. Neurotoxicol Teratol 66:94-101

63. Ideta-Otsuka M, Igarashi K, Narita M, Hirabayashi Y (2017) Epigenetic toxicity of environmental chemicals upon exposure during development- - bisphenol A and valproic acid may have epigenetic effects. Food Chem Toxicol 109:812-816

64. Thirtamara Rajamani K, Doherty-Lyons S, Bolden C, Willis D, Hoffman C, Zelikoff J et al (2013) Prenatal and early-life exposure to high-level diesel exhaust particles leads to increased locomotor activity and repetitive behaviors in mice: diesel exhaust particles and autism. Autism Res. 6:248-257

65. Yokota S, Mizuo K, Moriya N, Oshio S, Sugawara I, Takeda K (2009) Effect of prenatal exposure to diesel exhaust on dopaminergic system in mice. Neurosci Lett 449:38-41

66. Yokota S, Moriya N, Iwata M, Umezawa M, Oshio S, Takeda K (2013) Exposure to diesel exhaust during fetal period affects behavior and neurotransmitters in male offspring mice. J Toxicol Sci 38:13-23

67. Yokota S, Takashima H, Ohta R, Saito Y, Miyahara T, Yoshida Y et al (2011) Nasal instillation of nanoparticle-rich diesel exhaust particles slightly affects emotional behavior and learning capability in rats. J Toxicol Sci 36:267-276

68. Shaw JLA, Judy JD, Kumar A, Bertsch P, Wang M-B, Kirby JK (2017) Incorporating transgenerational epigenetic inheritance into ecological risk assessment frameworks. Environ Sci Technol 51:9433-9445

69. Klengel T, Dias BG, Ressler KJ (2016) Models of intergenerational and transgenerational transmission of risk for psychopathology in mice. Neuropsychopharmacology 41:219-231

70. Knecht AL, Truong L, Simonich MT, Tanguay RL (2017) Developmental benzo[a]pyrene (B[a]P) exposure impacts larval behavior and impairs adult learning in zebrafish. Neurotoxicol Teratol 59:27-34

71. Carvan MJ 3rd, Kalluvila TA, Klingler RH, Larson JK, Pickens M, MoraZamorano FX et al (2017) Mercury-induced epigenetic transgenerational inheritance of abnormal neurobehavior is correlated with sperm epimutations in zebrafish. PLoS ONE 12:e0176155

72. Aschner M (2002) Neurotoxic mechanisms of fish-borne methylmercury. Environ Toxicol Pharmacol 12:101-104

73. Beauvais SL, Jones SB, Parris JT, Brewer SK, Little EE (2001) Cholinergic and behavioral neurotoxicity of carbaryl and cadmium to larval rainbow trout (Oncorhynchus mykiss). Ecotoxicol Environ Saf 49:84-90

74. Bush J, Moffatt S, Dunn C (2001) 'Even the birds round here cough': stigma, air pollution and health in Teesside. Health Place. 7:47-56

75. Llacuna S, Gorriz A, Sanpera C, Nadal J (1995) Metal accumulation in three species of passerine birds (Emberiza cia, Parus major, and Turdus merula) subjected to air pollution from a coal-fired power plant. Arch Environ Contam Toxicol 28:298-303

76. Richard Pilsner J, Lazarus AL, Nam D-H, Letcher RJ, Sonne C, Dietz R et al (2010) Mercury-associated DNA hypomethylation in polar bear brains via the LUminometric Methylation Assay: a sensitive method to study epigenetics in wildlife. Mol Ecol 19:307-314

77. Carpenter DO (2001) Effects of metals on the nervous system of humans and animals. Int J Occup Med Environ Health 14:209-218

78. Basu N, Head J, Nam D-H, Pilsner JR, Carvan MJ, Chan HM et al (2013) Effects of methylmercury on epigenetic markers in three model species: mink, chicken and yellow perch. Comp Biochem Physiol C: Toxicol Pharmacol 157:322-327

79. Harris KDM, Bartlett NJ, Lloyd VK (2012) Daphnia as an emerging epigenetic model organism. Genet Res Int. 2012:147892

80. Sih A, Bell A, Johnson JC (2004) Behavioral syndromes: an ecological and evolutionary overview. Trends Ecol Evol 19:372-378

81. Verhoeven KJF, vonHoldt BM, Sork VL (2016) Epigenetics in ecology and evolution: what we know and what we need to know. Mol Ecol 25:1631-1638

82. Porterfield SP (2000) Thyroidal dysfunction and environmental chemicals-potential impact on brain development. Environ Health Perspect 108(Suppl 3):433-438

83. Colborn T (2004) Neurodevelopment and endocrine disruption. Environ Health Perspect 112:944-949

84. Brouwer A, Longnecker MP, Birnbaum LS, Cogliano J, Kostyniak P, Moore J et al (1999) Characterization of potential endocrine-related health effects at low-dose levels of exposure to PCBs. Environ Health Perspect 107(Suppl 4):639-649

85. Modesto T, Tiemeier H, Peeters RP, Jaddoe VWV, Hofman A, Verhulst FC et al (2015) Maternal mild thyroid hormone insufficiency in early pregnancy and attention-deficit/hyperactivity disorder symptoms in children. JAMA Pediatr. 169:838-845 
86. Román GC, Ghassabian A, Bongers-Schokking JJ, Jaddoe VWV, Hofman A, de Rijke YB et al (2013) Association of gestational maternal hypothyroxinemia and increased autism risk. Ann Neurol 74:733-742

87. Bergman Å, Heindel JJ, Jobling S, Kidd K, Zoeller TR, Organization WH et al. State of the science of endocrine disrupting chemicals 2012: summary for decision-makers. World Health Organization; 2013. http://apps.who.int/iris/bitstream/10665/78102/1/WHO_HSE_PHE_ IHE_2013.1_eng.pdf

88. Crews D, Gore AC (2011) Life imprints: living in a contaminated world. Environ Health Perspect 119:1208-1210

89. van der Ven K, Keil D, Moens LN, Hummelen PV, van Remortel P, Maras M et al (2006) Effects of the antidepressant mianserin in zebrafish: molecular markers of endocrine disruption. Chemosphere 65:1836-1845

90. Ferraz da Silva I, Freitas-Lima LC, Graceli JB, Rodrigues LCM (2017) Organotins in neuronal damage, brain function, and behavior: a short review. Front Endocrinol. 8:366

91. Du Z-H, Xia J, Sun X-C, Li X-N, Zhang C, Zhao H-S et al (2017) A novel nuclear xenobiotic receptors (AhR/PXR/CAR)-mediated mechanism of DEHP-induced cerebellar toxicity in quails (Coturnix japonica) via disrupting CYP enzyme system homeostasis. Environ Pollut 226:435-443

92. Zoeller RT, Crofton KM (2000) Thyroid hormone action in fetal brain development and potential for disruption by environmental chemicals. Neurotoxicology 21:935-945

93. Frye $C A, B o E$, Calamandrei $G$, Calzà L, Dessì-Fulgheri F, Fernández M et al (2012) Endocrine disrupters: a review of some sources, effects, and mechanisms of actions on behaviour and neuroendocrine systems. J Neuroendocrinol 24:144-159

94. Campinho MA, Saraiva J, Florindo C, Power DM (2014) Maternal thyroid hormones are essential for neural development in zebrafish. Mol Endocrinol 28:1136-1149

95. Wang F, Fang M, Hinton DE, Chernick M, Jia S, Zhang Y et al (2018) Increased coiling frequency linked to apoptosis in the brain and altered thyroid signaling in zebrafish embryos (Danio rerio) exposed to the PBDE metabolite 6-OH-BDE-47. Chemosphere 198:342-350

96. Wang Q, Lai NL-S, Wang X, Guo Y, Lam PK-S, Lam JC-W et al (2015) Bioconcentration and transfer of the organophorous flame retardant 1,3-dichloro-2-propyl phosphate causes thyroid endocrine disruption and developmental neurotoxicity in zebrafish larvae. Environ Sci Technol 49:5123-5132

97. Chen X, Huang C, Wang X, Chen J, Bai C, Chen Y et al (2012) BDE-47 disrupts axonal growth and motor behavior in developing zebrafish. Aquat Toxicol 120-121:35-44

98. Stewart AM, Braubach O, Spitsbergen J, Gerlai R, Kalueff AV (2014) Zebrafish models for translational neuroscience research: from tank to bedside. Trends Neurosci 37:264-278

99. Kalueff AV, Stewart AM, Gerlai R (2014) Zebrafish as an emerging model for studying complex brain disorders. Trends Pharmacol Sci 35:63-75

100. Denver RJ, Pavgi S, Shi YB (1997) Thyroid hormone-dependent gene expression program for Xenopus neural development. J Biol Chem 272:8179-8188

101. Ehrsam M, Knutie SA, Rohr JR (2016) The herbicide atrazine induces hyperactivity and compromises tadpole detection of predator chemical cues. Environ Toxicol Chem 35:2239-2244

102. Balbi T, Franzellitti S, Fabbri R, Montagna M, Fabbri E, Canesi L (2016) Impact of bisphenol A (BPA) on early embryo development in the marine mussel Mytilus galloprovincialis: effects on gene transcription. Environ Pollut 218:996-1004

103. Matsushima A, Ryan K, Shimohigashi Y, Meinertzhagen IA (2013) An endocrine disruptor, bisphenol $A$, affects development in the protochordate Ciona intestinalis: hatching rates and swimming behavior alter in a dose-dependent manner. Environ Pollut 173:257-263

104. Amaral Mendes JJ (2002) The endocrine disrupters: a major medical challenge. Food Chem Toxicol 40:781-788

105. Segner H, Caroll K, Fenske M, Janssen CR, Maack G, Pascoe D et al (2003) Identification of endocrine-disrupting effects in aquatic vertebrates and invertebrates: report from the European IDEA project. Ecotoxicol Environ Saf 54:302-314
106. Ward AJW, Thistle M, Ghandi K, Currie S (2013) Copper interacts with nonylphenol to cancel the effect of nonylphenol on fish chemosensory behaviour. Aquat Toxicol 142-143:203-209

107. Fent $\mathrm{K}$ (2004) Ecotoxicological effects at contaminated sites. Toxicology 205:223-240

108. Schmidt K, Staaks GBO, Pflugmacher S, Steinberg CEW (2005) Impact of PCB mixture (Aroclor 1254) and TBT and a mixture of both on swimming behavior, body growth and enzymatic biotransformation activities (GST) of young carp (Cyprinus carpio). Aquat Toxicol 71:49-59

109. Casida JE (2009) Pest toxicology: the primary mechanisms of pesticide action. Chem Res Toxicol 22:609-619

110. Timbrell JA (2008) Principles of biochemical toxicology. CRC Press, New York

111. Bloomquist JR (1996) Ion channels as targets for insecticides. Annu Rev Entomol 41:163-190

112. Narahashi T, Frey JM, Ginsburg KS, Roy ML (1992) Sodium and GABAactivated channels as the targets of pyrethroids and cyclodienes. Toxicol Lett 64:429-436

113. Casida JE (1993) Insecticide action at the GABA-gated chloride channel: recognition, progress, and prospects. Arch Insect Biochem Physiol 22:13-23

114. Casida JE (2018) Neonicotinoids and other insect nicotinic receptor competitive modulators: progress and prospects. Annu Rev Entomol 63:125-144

115. Blacquière T, Smagghe G, van Gestel CAM, Mommaerts V (2012) Neonicotinoids in bees: a review on concentrations, side-effects and risk assessment. Ecotoxicology 21:973-992

116. Simon-Delso N, Amaral-Rogers V, Belzunces LP, Bonmatin JM, Chagnon M, Downs C et al (2015) Systemic insecticides (neonicotinoids and fipronil): trends, uses, mode of action and metabolites. Environ Sci Pollut Res Int 22:5-34

117. Kretschmann A, Ashauer R, Hitzfeld K, Spaak P, Hollender J, Escher BI (2011) Mechanistic toxicodynamic model for receptor-mediated toxicity of diazoxon, the active metabolite of diazinon, in Daphnia magna. Environ Sci Technol 45:4980-4987

118. de Bruijn J, Hermens J (1991) Qualitative and quantitative modelling of toxic effects of organophosphorous compounds to fish. Sci Total Environ 109-110:441-455

119. Keizer J, D'Agostino G, Nagel R, Volpe T, Gnemi P, Vittozzi L (1995) Enzymological differences of AChE and diazinon hepatic metabolism: correlation of in vitro data with the selective toxicity of diazinon to fish species. Sci Total Environ 171:213-220

120. Kretschmann A, Ashauer R, Preuss TG, Spaak P, Escher BI, Hollender J (2011) Toxicokinetic model describing bioconcentration and biotransformation of diazinon in Daphnia magna. Environ Sci Technol 45:4995-5002

121. Ashauer R, Hintermeister A, Caravatti I, Kretschmann A, Escher BI (2010) Toxicokinetic and toxicodynamic modeling explains carry-over toxicity from exposure to diazinon by slow organism recovery. Environ Sci Technol 44:3963-3971

122. Ashauer R, O'Connor I, Escher BI (2017) Toxic mixtures in time-the sequence makes the poison. Environ Sci Technol 51:3084-3092

123. Bal-Price A, Hogberg HT, Crofton KM, Daneshian M, FitzGerald RE, Fritsche E et al (2018) Recommendation on test readiness criteria for new approach methods in toxicology: exemplified for developmental neurotoxicity. Altex. https://doi.org/10.14573/altex.1712081

124. de Groot MWGDM, Westerink RHS, Dingemans MML (2013) Don't judge a neuron only by its cover: neuronal function in in vitro developmental neurotoxicity testing. Toxicol Sci 132:1-7

125. Legradi J, van Pomeren M, Dahlberg A-K, Legler J (2017) Effects of hydroxylated polybrominated diphenyl ethers in developing zebrafish are indicative of disruption of oxidative phosphorylation. Int J Mol Sci. https://doi.org/10.3390/ijms18050970

126. Racz PI, Wildwater M, Rooseboom M, Kerkhof E, Pieters R, Yebra-Pimentel ES et al (2017) Application of Caenorhabditis elegans (nematode) and Danio rerio embryo (zebrafish) as model systems to screen for developmental and reproductive toxicity of Piperazine compounds. Toxicol In Vitro 44:11-16

127. van der Oost R, Sileno G, Suárez-Muñoz M, Nguyen MT, Besselink H, Brouwer A (2017) SIMONI (Smart Integrated Monitoring) as a novel 
bioanalytical strategy for water quality assessment: part I — model design and effect-based trigger values. Environ Toxicol Chem 36:2385-2399

128. Monzel AS, Smits LM, Hemmer K, Hachi S, Moreno EL, van Wuellen T et al (2018) Derivation of human midbrain-specific organoids from neuroepithelial stem cells. Stem Cell Rep 8:1144-1154

129. Tukker AM, van Groot MWGDM, Wijnolts FMJ, Kasteel EEJ, Hondebrink L, Westerink RHS (2016) Is the time right for in vitro neurotoxicity testing using human iPSC-derived neurons? ALTEX 33:261-271

130. Monzel AS, Smits LM, Hemmer K, Hachi S, Moreno EL, van Wuellen T et al (2017) Derivation of human midbrain-specific organoids from neuroepithelial stem cells. Stem Cell Rep 8:1144-1154

131. Maltby L, Blake N, Brock TCM, van den Brink PJ (2005) Insecticide species sensitivity distributions: importance of test species selection and relevance to aquatic ecosystems. Environ Toxicol Chem 24:379-388

132. Colović MB, Krstić DZ, Lazarević-Pašti TD, Bondžić AM, Vasić VM (2013) Acetylcholinesterase inhibitors: pharmacology and toxicology. Curr Neuropharmacol 11:315-335

133. Olsen ML, Khakh BS, Skatchkov SN, Zhou M, Lee CJ, Rouach N (2015) New insights on astrocyte ion channels: critical for homeostasis and neuron-glia signaling. J Neurosci 35:13827-13835

134. Aschner M, Ceccatelli S, Daneshian M, Fritsche E, Hasiwa N, Hartung Tet al (2017) Reference compounds for alternative test methods to indicate developmental neurotoxicity (DNT) potential of chemicals: example lists and criteria for their selection and use. Altex 34:49-74

135. Pei Y, Peng J, Behl M, Sipes NS, Shockley KR, Rao MS et al (2016) Comparative neurotoxicity screening in human iPSC-derived neural stem cells, neurons and astrocytes. Brain Res 1638:57-73

136. Chambers SM, Fasano CA, Papapetrou EP, Tomishima M, Sadelain M Studer $L$ (2009) Highly efficient neural conversion of human ES and iPS cells by dual inhibition of SMAD signaling. Nat Biotechnol 27:275-280

137. Hayess K, Riebeling C, Pirow R, Steinfath M, Sittner D, Slawik B et al (2013) The DNT-EST: a predictive embryonic stem cell-based assay for developmental neurotoxicity testing in vitro. Toxicology 314:135-147

138. Wu X, Yang X, Majumder A, Swetenburg R, Goodfellow FT, Bartlett MG et al (2017) From the cover: astrocytes are protective against chlorpyrifos developmental neurotoxicity in human pluripotent stem cell-derived astrocyte-neuron cocultures. Toxicol Sci 157:410-420

139. Singh S, Srivastava A, Kumar V, Pandey A, Kumar D, Rajpurohit CS et al (2016) Stem cells in neurotoxicology/developmental neurotoxicology: current scenario and future prospects. Mol Neurobiol 53:6938-6949

140. Wheeler HE, Wing C, Delaney SM, Komatsu M, Dolan ME (2015) Modeling chemotherapeutic neurotoxicity with human induced pluripotent stem cell-derived neuronal cells. PLoS ONE 10:e0118020

141. Ryan KR, Sirenko O, Parham F, Hsieh J-H, Cromwell EF, Tice RR et al (2016) Neurite outgrowth in human induced pluripotent stem cellderived neurons as a high-throughput screen for developmental neurotoxicity or neurotoxicity. Neurotoxicology 53:271-281

142. Meamar R, Dehghani L, Karamali F (2012) Toxicity effects of methamphetamine on embryonic stem cell-derived neuron. J Res Med Sci $17: 470-474$

143. Cao WS, Livesey JC, Halliwell RF (2015) An evaluation of a human stem cell line to identify risk of developmental neurotoxicity with antiepileptic drugs. Toxicol In Vitro 29:592-599

144. Hubbard K, Beske P, Lyman M, McNutt P (2015) Functional evaluation of biological neurotoxins in networked cultures of stem cell-derived central nervous system neurons. JVis Exp. https://doi.org/10.3791/52361

145. Rocha RA, Gimeno-Alcañiz JV, Martín-Ibañez R, Canals JM, Vélez D, Devesa $\vee(2011)$ Arsenic and fluoride induce neural progenitor cell apoptosis. Toxicol Lett 203:237-244

146. Gjorevski N, Ranga A, Lutolf MP (2014) Bioengineering approaches to guide stem cell-based organogenesis. Development 141:1794-1804

147. Lee C-T, Bendriem RM, Wu WW, Shen R-F (2017) 3D brain Organoids derived from pluripotent stem cells: promising experimental models for brain development and neurodegenerative disorders. J Biomed Sci 24:59

148. McComish SF, Caldwell MA (2018) Generation of defined neural populations from pluripotent stem cells. Philos Trans R Soc Lond B Biol Sci. https://doi.org/10.1098/rstb.2017.0214

149. Frega M, van Gestel SHC, Linda K, van der Raadt J, Keller J, Van Rhijn J-R et al (2017) Rapid neuronal differentiation of induced pluripotent stem cells for measuring network activity on micro-electrode arrays. J Vis Exp. https://doi.org/10.3791/54900

150. Ogorevc J, Orehek S, Dovč P (2016) Cellular reprogramming in farm animals: an overview of iPSC generation in the mammalian farm animal species. J Anim Sci Biotechnol 7:10

151. Betts DH, Tobias IC (2015) Canine pluripotent stem cells: are they ready for clinical applications? Front Vet Sci 2:41

152. Verma R, Liu J, Holland MK, Temple-Smith P, Williamson M, Verma PJ (2013) Nanog is an essential factor for induction of pluripotency in somatic cells from endangered felids. Bioresrourc Open Access 2:72-76

153. Ramaswamy K, Yik WY, Wang X-M, Oliphant EN, Lu W, Shibata D et al (2015) Derivation of induced pluripotent stem cells from orangutan skin fibroblasts. BMC Res Notes 8:577

154. Transdifferentiation — Latest research and news. Nature https://www. nature.com/subjects/transdifferentiation. Accessed 3 Aug 2018

155. Arini A, Mittal K, Basu N (2018) Cell-free assays in environmental toxicology. In: Garcia-Reyero N, Murphy CA (eds) A systems biology approach to advancing adverse outcome pathways for risk assessment. Springer International Publishing, Cham, pp 31-41

156. Arini A, Mittal K, Dornbos P, Head J, Rutkiewicz J, Basu N (2017) A cell-free testing platform to screen chemicals of potential neurotoxic concern across twenty vertebrate species. Environ Toxicol Chem 36:3081-3090

157. Basu N, Ta CA, Waye A, Mao J, Hewitt M, Arnason JT et al (2009) Pulp and paper mill effluents contain neuroactive substances that potentially disrupt neuroendocrine control of fish reproduction. Environ Sci Technol 43:1635-1641

158. Arini A, Cavallin JE, Berninger JP, Marfil-Vega R, Mills M, Villeneuve DL et al (2016) In vivo and In vitro neurochemical-based assessments of wastewater effluents from the Maumee River area of concern. Environ Pollut 211:9-19

159. Tierney KB, Baldwin DH, Hara TJ, Ross PS, Scholz NL, Kennedy CJ (2010) Olfactory toxicity in fishes. Aquat Toxicol 96:2-26

160. Ottoson D (1955) Analysis of the electrical activity of the olfactory epithelium. Acta Physiol Scand Suppl 35:1-83

161. Caprio J (1988) Peripheral filters and chemoreceptor cells in fishes. Sensory biology of aquatic animals. Springer, New York, pp 313-338

162. Carr WES (1988) The molecular nature of chemical stimuli in the aquatic environment. In: Atema J, Fay RR, Popper AN, Tavolga WN (eds) Sensory biology of aquatic animals. Springer, New York, pp 3-27

163. Zhu P, Fajardo O, Shum J, Zhang Schärer Y-P, Friedrich RW (2012) Highresolution optical control of spatiotemporal neuronal activity patterns in zebrafish using a digital micromirror device. Nat Protoc 7:1410-1425

164. Tabor R, Yaksi E, Weislogel J-M, Friedrich RW (2004) Processing of odor mixtures in the zebrafish olfactory bulb. J Neurosci 24:6611-6620

165. Baier H, Korsching S (1994) Olfactory glomeruli in the zebrafish form an invariant pattern and are identifiable across animals. J Neurosci 14:219-230

166. Friedrich RW, Wiechert MT (2014) Neuronal circuits and computations: pattern decorrelation in the olfactory bulb. FEBS Lett 588:2504-2513

167. Sato Y, Miyasaka N, Yoshihara Y (2007) Hierarchical regulation of odorant receptor gene choice and subsequent axonal projection of olfactory sensory neurons in zebrafish. J Neurosci 27:1606-1615

168. Saraiva LR, Ahuja G, Ivandic I, Syed AS, Marioni JC, Korsching SI et al (2015) Molecular and neuronal homology between the olfactory systems of zebrafish and mouse. Sci Rep 5:11487

169. Packard A, Schnittke N, Romano R-A, Sinha S, Schwob JE (2011) DeltaNp63 regulates stem cell dynamics in the mammalian olfactory epithelium. J Neurosci 31:8748-8759

170. Schnittke N, Herrick DB, Lin B, Peterson J, Coleman JH, Packard Al et al (2015) Transcription factor p63 controls the reserve status but not the stemness of horizontal basal cells in the olfactory epithelium. Proc Natl Acad Sci USA 112:E5068-E5077

171. Grant WM, Thomas CC. Toxicology of the eye, third edition. J Toxicol Cutaneous Ocul Toxicol. Taylor \& Francis; 1987;6: 155-156

172. Fox DA (2015) Retinal and visual system: occupational and environmental toxicology. Handb Clin Neurol. 131:325-340

173. Matsui Jl, Egana AL, Sponholtz TR, Adolph AR, Dowling JE (2006) Effects of ethanol on photoreceptors and visual function in developing zebrafish. Invest Ophthalmol Vis Sci 47:4589-4597 
174. Mela M, Cambier S, Mesmer-Dudons N, Legeay A, Grötzner SR, de Oliveira Ribeiro CA et al (2010) Methylmercury localization in Danio rerio retina after trophic and subchronic exposure: a basis for neurotoxicology. Neurotoxicology 31:448-453

175. Mela M, Grötzner SR, Legeay A, Mesmer-Dudons N, Massabuau J-C, Ventura DF et al (2012) Morphological evidence of neurotoxicity in retina after methylmercury exposure. Neurotoxicology 33:407-415

176. Tanan CL, Ventura DF, de Souza JM, Grotzner SR, Mela M, Gouveia A Jr et al (2006) Effects of mercury intoxication on the response of horizontal cells of the retina of thraira fish (Hoplias malabaricus). Braz J Med Biol Res 39:987-995

177. Quintaneiro C, Soares AMVM, Monteiro MS (2018) Effects of the herbicides linuron and S-metolachlor on Perez's frog embryos. Chemosphere 194:595-601

178. Roy NM, Carneiro B, Ochs J (2016) Glyphosate induces neurotoxicity in zebrafish. Environ Toxicol Pharmacol 42:45-54

179. Marigoudar SR, Mohan D, Nagarjuna A, Karthikeyan P (2018) Biomarker and histopathological responses of Lates calcarifer on exposure to sub lethal concentrations of chlorpyrifos. Ecotoxicol Environ Saf 148:327-335

180. Kirla KT, Groh KJ, Steuer AE, Poetzsch M, Banote RK, Stadnicka-Michalak $J$ et al (2016) From the cover: zebrafish larvae are insensitive to stimulation by cocaine: importance of exposure route and toxicokinetics. Toxicol Sci 154:183-193

181. Perlman I (2018) The electroretinogram: ERG in Webvision: the organization of the retina and visual system. Moran Eye Center, Lake

182. Seeliger MW, Rilk A, Neuhauss SCF (2002) Ganzfeld ERG in zebrafish larvae. Doc Ophthalmol 104:57-68

183. Schuster S, Machnik P, Schulze W (2011) Behavioral assessment of the visual capabilities of fish. Encyclop Fish Physiol 1:143-149

184. Brockerhoff SE (2006) Measuring the optokinetic response of zebrafish larvae. Nat Protoc 1:2448-2451

185. Maurer CM, Huang Y-Y, Neuhauss SCF (2011) Application of zebrafish oculomotor behavior to model human disorders. Rev Neurosci 22:5-16

186. Neuhauss SCF (2003) Behavioral genetic approaches to visual system development and function in zebrafish. J Neurobiol 54:148-160

187. Steyger PS, Cunningham LL, Esquivel CR, Watts KL, Zuo J (2018) Editorial: cellular mechanisms of ototoxicity. Front Cell Neurosci 12:75

188. Coffin AB, Ramcharitar J (2016) Chemical ototoxicity of the fish inner ear and lateral line. Adv Exp Med Biol 877:419-437

189. McNeil PL, Boyle D, Henry TB, Handy RD, Sloman KA (2014) Effects of metal nanoparticles on the lateral line system and behaviour in early life stages of zebrafish (Danio rerio). Aquat Toxicol 152:318-323

190. Olivari FA, Hernández PP, Allende ML (2008) Acute copper exposure induces oxidative stress and cell death in lateral line hair cells of zebrafish larvae. Brain Res 1244:1-12

191. Bhandiwad AA, Zeddies DG, Raible DW, Rubel EW, Sisneros JA (2013) Auditory sensitivity of larval zebrafish (Danio rerio) measured using a behavioral prepulse inhibition assay. J Exp Biol 216:3504-3513

192. Buck LMJ, Winter MJ, Redfern WS, Whitfield TT (2012) Ototoxin-induced cellular damage in neuromasts disrupts lateral line function in larval zebrafish. Hear Res 284:67-81

193. Liu X, Lin J, Zhang Y, Guo N, Li Q (2018) Sound shock response in larval zebrafish: a convenient and high-throughput assessment of auditory function. Neurotoxicol Teratol 66:1-7

194. Groneberg AH, Herget U, Ryu S, De Marco RJ (2015) Positive taxis and sustained responsiveness to water motions in larval zebrafish. Front Neural Circuits 9:9

195. Olive R, Wolf S, Dubreuil A, Bormuth V, Debrégeas G, Candelier R (2016) Rheotaxis of larval zebrafish: behavioral study of a multi-sensory process. Front Syst Neurosci 10:14

196. Oteiza P, Odstrcil I, Lauder G, Portugues R, Engert F (2017) A novel mechanism for mechanosensory-based rheotaxis in larval zebrafish. Nature 547:445-448

197. Stengel D, Zindler F, Braunbeck T (2017) An optimized method to assess ototoxic effects in the lateral line of zebrafish (Danio rerio) embryos. Comp Biochem Physiol C 193:18-29

198. Froehlicher M, Liedtke A, Groh KJ, Neuhauss SCF, Segner H, Eggen RIL (2009) Zebrafish (Danio rerio) neuromast: promising biological endpoint linking developmental and toxicological studies. Aquat Toxicol 95:307-319
199. Ladich F, Fay RR (2013) Auditory evoked potential audiometry in fish. Rev Fish Biol Fish 23:317-364

200. Stengel D, Wahby S, Braunbeck T (2018) In search of a comprehensible set of endpoints for the routine monitoring of neurotoxicity in vertebrates: sensory perception and nerve transmission in zebrafish (Danio rerio) embryos. Environ Sci Pollut Res Int 25:4066-4084

201. Grienberger C, Konnerth A (2012) Imaging calcium in neurons. Neuron 73:862-885

202. Renninger SL, Orger MB (2013) Two-photon imaging of neural population activity in zebrafish. Methods 62:255-267

203. vom Berg-Maurer CM, Trivedi CA, Bollmann JH, De Marco RJ, Ryu S (2016) The severity of acute stress is represented by increased synchronous activity and recruitment of hypothalamic CRH neurons. J Neurosci 36:3350-3362

204. Del Bene F, Wyart C (2012) Optogenetics: a new enlightenment age for zebrafish neurobiology. Dev Neurobiol 72:404-414

205. Garcia GR, Noyes PD, Tanguay RL (2016) Advancements in zebrafish applications for 21st century toxicology. Pharmacol Ther 161:11-21

206. Kokel D, Bryan J, Laggner C, White R, Cheung CYJ, Mateus R et al (2010) Rapid behavior-based identification of neuroactive small molecules in the zebrafish. Nat Chem Biol 6:231-237

207. Noyes PD, Haggard DE, Gonnerman GD, Tanguay RL (2015) Advanced morphological_behavioral test platform reveals neurodevelopmental defects in embryonic zebrafish exposed to comprehensive suite of halogenated and organophosphate flame retardants. Toxicol Sci 145:177-195

208. Reif DM, Truong L, Mandrell D, Marvel S, Zhang G, Tanguay RL (2016) High-throughput characterization of chemical-associated embryonic behavioral changes predicts teratogenic outcomes. Arch Toxicol 90:1459-1470

209. Triebskorn R, Adam S, Casper H, Honnen W, Pawert M, Schramm M et al (2002) Biomarkers as diagnostic tools for evaluating effects of unknown past water quality conditions on stream organisms. Ecotoxicology 11:451-465

210. Viarengo A, Ponzano E, Dondero F, Fabbri R (1997) A simple spectrophotometric method for metallothionein evaluation in marine organisms: an application to Mediterranean and Antarctic molluscs. Mar Environ Res 44:69-84

211. Mukhopadhyay I, Nazir A, Saxena DK, Chowdhuri DK (2003) Heat shock response: hsp70 in environmental monitoring. J Biochem Mol Toxicol $17: 249-254$

212. Rank J, Lehtonen KK, Strand J, Laursen M (2007) DNA damage, acetylcholinesterase activity and lysosomal stability in native and transplanted mussels (Mytilus edulis) in areas close to coastal chemical dumping sites in Denmark. Aquat Toxicol 84:50-61

213. Fossi MC (1994) Nondestructive biomarkers in ecotoxicology. Environ Health Perspect 102(Suppl 12):49-54

214. Allner B, Hennies M, Lerche CF, Schmidt T, Schneider K, Willner M et al (2016) Kinetic determination of vitellogenin induction in the epidermis of cyprinid and perciform fishes: evaluation of sensitive enzyme-linked immunosorbent assays. Environ Toxicol Chem 35:2916-2930

215. Küster E, Altenburger R (2006) Comparison of cholin- and carboxylesterase enzyme inhibition and visible effects in the zebra fish embryo bioassay under short-term paraoxon-methyl exposure. Biomarkers 11:341-354

216. Whitehead A, Anderson SL, Ramirez A, Wilson BW (2005) Cholinesterases in aquatic biomonitoring: assay optimization and species-specific characterization for a California native fish. Ecotoxicology 14:597-606

217. Kretschmann A, Ashauer R, Hollender J, Escher BI (2012) Toxicokinetic and toxicodynamic model for diazinon toxicity — mechanistic explanation of differences in the sensitivity of Daphnia magna and Gammarus pulex. Environ Toxicol Chem 31:2014-2022

218. Barriga-Vallejo C, Aguilera C, Cruz J, Banda-Leal J, Lazcano D, Mendoza R (2017) Ecotoxicological biomarkers in multiple tissues of the neotenic Ambystoma spp. for a non-lethal monitoring of contaminant exposure in wildlife and captive populations. Water Air Soil Pollut Focus. 228:415

219. Troiano AT, Grue CE (2016) Plasma cholinesterase activity as a biomarker for quantifying exposure of green sturgeon to carbaryl following applications to control burrowing shrimp in Washington State. Environ Toxicol Chem 35:2003-2015 
220. Ellman GL, Courtney KD, Andres V Jr, Feather-Stone RM (1961) A new and rapid colorimetric determination of acetylcholinesterase activity. Biochem Pharmacol 7:88-95

221. Neale PA, Escher BI (2013) Coextracted dissolved organic carbon has a suppressive effect on the acetylcholinesterase inhibition assay. Environ Toxicol Chem 32:1526-1534

222. Mineau P (Canadian Wildlife Service, Ottawa (Canada). National Wildlife Research (entre). Cholinesterase-inhibiting insecticides: their impact on wildlife and the environment. Chemicals in Agriculture (Netherlands). Elsevier; 1991. http://agris.fao.org/agris-search/search.do?recor $\mathrm{dID}=\mathrm{NL} 9204434$

223. Gagné F, Blaise C (2003) Effects of municipal effluents on serotonin and dopamine levels in the freshwater mussel Elliptio complanata. Comp Biochem Physiol C 136:117-125

224. Gagné F, Cejka P, André C, Hausler R, Blaise C (2007) Neurotoxicological effects of a primary and ozonated treated wastewater on freshwater mussels exposed to an experimental flow-through system. Comp Biochem Physiol C 146:460-470

225. Le Page Y, Vosges M, Servili A, Brion F, Kah O (2011) Neuroendocrine effects of endocrine disruptors in teleost fish. J Toxicol Environ Health B Crit Rev 14:370-386

226. Waye A, Trudeau VL (2011) Neuroendocrine disruption: more than hormones are upset. J Toxicol Environ Health B Crit Rev 14:270-291

227. Gesto M, Tintos A, Soengas JL, Míguez JM (2009) beta-Naphthoflavone and benzo(a)pyrene alter dopaminergic, noradrenergic, and serotonergic systems in brain and pituitary of rainbow trout (Oncorhynchus mykiss). Ecotoxicol Environ Saf 72:191-198

228. Robinson PD (2009) Behavioural toxicity of organic chemical contaminants in fish: application to ecological risk assessments (ERAs). Can J Fish Aquat Sci 66:1179-1188

229. Van Der Geest HG, Greve GD, de Haas EM, Scheper BB, Kraak MHS, Stuijfzand SC et al (1999) Hydropsyche angustipennis to copper and diazinon. Environ Toxicol Chem 18:1965-1971

230. Kokel D, Peterson RT (2011) Using the zebrafish photomotor response for psychotropic drug screening. Methods Cell Biol 105:517-524

231. Klüver N, König M, Ortmann J, Massei R, Paschke A, Kühne R et al (2015) Fish embryo toxicity test: identification of compounds with weak toxicity and analysis of behavioral effects to improve prediction of acute toxicity for neurotoxic compounds. Environ Sci Technol 49:7002-7011

232. Valente A, Huang K-H, Portugues R, Engert F (2012) Ontogeny of classical and operant learning behaviors in zebrafish. Learn Mem 19:170-177

233. Wang XH, Souders CL 2nd, Zhao YH, Martyniuk CJ (2018) Mitochondrial bioenergetics and locomotor activity are altered in zebrafish (Danio rerio) after exposure to the bipyridylium herbicide diquat. Toxicol Lett 283:13-20

234. Vignet C, Le Menach K, Lyphout L, Guionnet T, Frère L, Leguay D et al (2014) Chronic dietary exposure to pyrolytic and petrogenic mixtures of PAHs causes physiological disruption in zebrafish-part II: behavior Environ Sci Pollut Res Int 21:13818-13832

235. Vignet $C$, Trenkel VM, Vouillarmet A, Bricca G, Bégout $M-L$, Cousin X (2017) Changes in brain monoamines underlie behavioural disruptions after zebrafish diet exposure to polycyclic aromatic hydrocarbons environmental mixtures. Int J Mol Sci. https://doi.org/10.3390/ijms18030560

236. Hellou J, Cheeseman K, Desnoyers E, Johnston D, Jouvenelle M-L, Leonard J et al (2008) A non-lethal chemically based approach to investigate the quality of harbour sediments. Sci Total Environ 389:178-187

237. Sohn L, Brodie RJ, Couldwell G, Demmons E, Sturve J (2018) Exposure to a nicotinoid pesticide reduces defensive behaviors in a non-target organism, the rusty crayfish Orconectes rusticus. Ecotoxicology 27:900-907

238. Castro BB, Silva C, Macário IPE, Oliveira B, Gonçalves F, Pereira JL (2018) Feeding inhibition in Corbicula fluminea (O.F. Muller, 1774) as an effect criterion to pollutant exposure Perspectives for ecotoxicity screening and refinement of chemical control. Aquat Toxicol 196:25-34

239. Villa S, Di Nica V, Pescatore T, Bellamoli F, Miari F, Finizio A et al (2018) Comparison of the behavioural effects of pharmaceuticals and pesticides on Diamesa zernyi larvae (Chironomidae). Environ Pollut 238:130-139

240. Chevalier J, Harscoët E, Keller M, Pandard P, Cachot J, Grote M (2015) Exploration of Daphnia behavioral effect profiles induced by a broad range of toxicants with different modes of action. Environ Toxicol Chem 34:1760-1769

241. Araújo CVM, Moreira-Santos M, Ribeiro R (2016) Active and passive spatial avoidance by aquatic organisms from environmental stressors: a complementary perspective and a critical review. Environ Int 92-93:405-415

242. Rastetter N, Gerhardt A (2017) Continuous monitoring of avoidance behaviour with the earthworm Eisenia fetida. J Soils Sediments. https:// doi.org/10.1007/s11368-017-1791-4

243. Mitzel MR, Lin N, Whalen JK, Tufenkji N (2017) Chlamydomonas reinhardtii displays aversive swimming response to silver nanoparticles. Environ Sci Nano 4:1328-1338

244. Martin P, Bateson PPG (1993) Measuring behaviour: an introductory guide. Cambridge University Press, London

245. Langer-Jaesrich M, Kienle C, Köhler H-R, Gerhardt A (2010) Impairment of trophic interactions between zebrafish (Danio rerio) and midge larvae (Chironomus riparius) by chlorpyrifos. Ecotoxicology 19:1294-1301

246. Hunting ER, Mulder C, Kraak MHS, Breure AM, Admiraal W (2013) Effects of copper on invertebrate-sediment interactions. Environ Pollut 180:131-135

247. Gerhardt A, Svensson E (1994) Monitoring of behavioral patterns of aquatic organisms with an impedance conversion technique. Environ Intematlonal 20:209-219

248. Gerhardt A (1999) Recent trends in online biomonitoring for water quality control. Biomonitoring of polluted water reviews on actual topics environmental research forum. TTP Switzerland, Switzerland, pp 95-118

249. Harrison JW, Beecraft L, Smith REH (2018) Implications of irradiance exposure and non-photochemical quenching for multi-wavelength (bbe FluoroProbe) fluorometry. J Photochem Photobiol B 189:36-48

250. Lechelt M, Blohm W, Kirschneit B, Pfeiffer M, Gresens E, Liley J et al (2000) Monitoring of surface water by ultrasensitive Daphnia toximeter. Environ Toxicol 15:390-400

251. Jou L-J, Lin S-C, Chen B-C, Chen W-Y, Liao C-M (2013) Synthesis and measurement of valve activities by an improved online clam-based behavioral monitoring system. Comput Electron Agric. 90:106-118

252. Ragas A, Teuschler L, Posthuma L, Cowan C (2010) Human and ecological risk assessment of chemical mixtures. In: van Gestel C, Jonker M, Kammenga J, Laskowski R, Svendsen C (eds) Mixture toxicity. CRC Press, New York, pp 157-212

253. Kortenkamp A, Altenburger R (2010) Toxicity from combined exposure to chemicals. In: van Gestel C, Jonker M, Kammenga J, Laskowski R, Svendsen C (eds) Mixture toxicity. CRC Press, New York, pp 95-119

254. Backhaus T, Faust M (2012) Predictive environmental risk assessment of chemical mixtures: a conceptual framework. Environ Sci Technol 46:2564-2573

255. Kim S, Ji K, Lee S, Lee J, Kim J, Kim S et al (2011) Perfluorooctane sulfonic acid exposure increases cadmium toxicity in early life stage of zebrafish, Danio rerio. Environ Toxicol Chem 30:870-877

256. Fritsche E, Alm H, Baumann J, Geerts L, Håkansson H, Masjosthusmann S et al (2015) Literature review on in vitro and alternative developmental neurotoxicity (DNT) testing methods. EFSA Supporting Publications. Wiley Online Library, vol 12. http://onlinelibrary.wiley.com/doi/10.2903/ sp.efsa.2015.EN-778/full

257. Grandjean P, Landrigan PJ (2014) Neurobehavioural effects of developmental toxicity. Lancet Neurol 13:330-338

258. Relyea RA (2009) A cocktail of contaminants: how mixtures of pesticides at low concentrations affect aquatic communities. Oecologia 159:363-376

259. Scholz NL, Truelove NK, Labenia JS, Baldwin DH, Collier TK (2006) Doseadditive inhibition of chinook salmon acetylcholinesterase activity by mixtures of organophosphate and carbamate insecticides. Environ Toxicol Chem 25:1200-1207

260. Deneer JW (2000) Toxicity of mixtures of pesticides in aquatic systems. Pest Manag Sci 56:516-520

261. Laetz CA, Baldwin DH, Collier TK, Hebert V, Stark JD, Scholz NL (2009) The synergistic toxicity of pesticide mixtures: implications for risk assessment and the conservation of endangered Pacific salmon. Environ Health Perspect 117:348 
262. Pape-Lindstrom PA, Lydy MJ (1997) Synergistic toxicity of atrazine and organophosphate insecticides contravenes the response addition mixture model. Environ Toxicol Chem 16:2415-2420

263. Harbers JV, Huijbregts MAJ, Posthuma L, Van de Meent D (2006) Estimating the impact of high-production-volume chemicals on remote ecosystems by toxic pressure calculation. Environ Sci Technol 40:1573-1580

264. De Zwart D, Posthuma L (2005) Complex mixture toxicity for single and multiple species: proposed methodologies. Environ Toxicol Chem 24:2665-2676

265. Van der Oost, Postma R, Pldzdol J (2016) Ecologische Sleutelfactor Toxiciteit. Deel 1: methode voor het in beeld brengen van de toxiciteit. STOWA Report 2016-15A. http://www.stowa.nl/projecten/ecologisch e_sleutelfactor_8_toxiciteit_ontwikkeling_instrument_voor_ecolo gische_effectanalyse_toxiciteit_

266. Barceló D (2007) Effect-directed analysis of key toxicants in european river basins: a review (pp 9). Environ Sci Pollut Res 14:30-38

267. Brack W, Schirmer K, Erdinger L, Hollert H (2005) Effect-directed analysis of mutagens and ethoxyresorufin-O-deethylase inducers in aquatic sediments. Environ Toxicol Chem 24:2445-2458

268. Hecker M, Hollert H (2009) Effect-directed analysis (EDA) in aquatic ecotoxicology: state of the art and future challenges. Environ Sci Pollut Res Int 16:607-613

269. Qu G, Shi J, Wang T, Fu J, Li Z, Wang P et al (2011) Identification of tetrabromobisphenol A diallyl ether as an emerging neurotoxicant in environmental samples by bioassay-directed fractionation and HPLC-APCI-MS/MS. Environ Sci Technol 45:5009-5016

270. Bal-Price A, Pistollato F, Sachana M, Bopp SK, Munn S, Worth A (2018) Strategies to improve the regulatory assessment of developmental neurotoxicity (DNT) using in vitro methods. Toxicol Appl Pharmacol. https://doi.org/10.1016/j.taap.2018.02.008

271. Ouyang X, Leonards PEG, Tousova Z, Slobodnik J, de Boer J, Lamoree MH (2016) Rapid screening of acetylcholinesterase inhibitors by effectdirected analysis using $L C \times L C$ fractionation, a high throughput in vitro assay, and parallel identification by time of flight mass spectrometry. Anal Chem 88:2353-2360. https://doi.org/10.1021/acs.analchem.5b043 11

272. Stütz L, Weiss SC, SchulzW, Schwack W, Winzenbacher R (2017) Selective two-dimensional effect-directed analysis with thin-layer chromatography. J Chromatogr A 1524:273-282

273. Buenafe OE, Orellana-Paucar A, Maes J, Huang H, Ying X, De Borggraeve W et al (2013) Tanshinone IIA exhibits anticonvulsant activity in zebrafish and mouse seizure models. ACS Chem Neurosci 4:1479-1487

274. Di Paolo C, Seiler T-B, Keiter S, Hu M, Muz M, Brack W et al (2015) The value of zebrafish as an integrative model in effect-directed analysis-a review. Environ Sci Eur 27:8

275. Orellana-Paucar AM, Serruys A-SK, Afrikanova T, Maes J, De Borggraeve W, Alen J et al (2012) Anticonvulsant activity of bisabolene sesquiterpenoids of Curcuma longa in zebrafish and mouse seizure models. Epilepsy Behav 24:14-22

276. Fabel S, Niessner R, Weller MG (2005) Effect-directed analysis by highperformance liquid chromatography with gas-segmented enzyme inhibition. J Chromatogr A 1099:103-110

277. Ingkaninan K, de Best CM, van der Heijden R, Hofte AJP, Karabatak B (2000) High-performance liquid chromatography with on-line coupled UV, mass spectrometric and biochemical detection for identification of acetylcholinesterase inhibitors from natural products. J Chromatogr A 872:61-73

278. Collins FS, Gray GM, Bucher JR (2008) Toxicology. Transforming environmental health protection. Science 319:906-907

279. Epa US (2015) ORD. Toxicity forecasting. https://www.epa.gov/chemi cal-research/toxicity-forecasting

280. EBI Web Team (2018) ChEMBL. https://www.ebi.ac.uk/chembl/. Accessed 3 Aug 2018

281. The PubChem Project. https://pubchem.ncbi.nlm.nih.gov/. Accessed 3 Aug 2018

282. Richard AM, Judson RS, Houck KA, Grulke CM, Volarath P, Thillainadarajah I et al (2016) ToxCast chemical landscape: paving the road to 21st century toxicology. Chem Res Toxicol 29:1225-1251
283. Valdivia P, Martin M, LeFew WR, Ross J, Houck KA, Shafer TJ (2014) Multiwell microelectrode array recordings detect neuroactivity of ToxCast compounds. Neurotoxicology 44:204-217

284. Frank CL, Brown JP, Wallace K, Mundy WR, Shafer TJ (2017) From the cover: developmental neurotoxicants disrupt activity in cortical networks on microelectrode arrays: results of screening 86 compounds during neural network formation. Toxicol Sci 160:121-135

285. Tardiff DF, Jui NT, Khurana V, Tambe MA, Thompson ML, Chung CY et al (2013) Yeast reveal a "druggable" Rsp5/Nedd4 network that ameliorates a-synuclein toxicity in neurons. Science 342:979-983

286. Tardiff DF, Lindquist S (2013) Phenotypic screens for compounds that target the cellular pathologies underlying Parkinson's disease. Drug Discov Today Technol 10:e121-e128

287. Xi Y, Yu M, Godoy R, Hatch G, Poitras L, Ekker M (2011) Transgenic zebrafish expressing green fluorescent protein in dopaminergic neurons of the ventral diencephalon. Dev Dyn 240:2539-2547

288. Parkinson Disease, Secondary-MeSH—NCBI. https://www.ncbi.nlm.nih. gov/mesh/68010302. Accessed 3 Aug 2018

289. Pubchem. PubChem Classification Browser. https://pubchem.ncbi.nlm. nih.gov/classification/. Accessed 3 Aug 2018

290. Epa US, ORD (2016) Downloadable Computational Toxicology Data. https://www.epa.gov/chemical-research/downloadable-computatio nal-toxicology-data

291. Chemistry Dashboard| Home. https://comptox.epa.gov/dashboard/. Accessed 3 Aug 2018

292. Williams AJ, Grulke CM, Edwards J, McEachran AD, Mansouri K, Baker NC et al (2017) The CompTox Chemistry Dashboard: a community data resource for environmental chemistry. J Cheminform 9:61

293. Shah I, Liu J, Judson RS, Thomas RS, Patlewicz G (2016) Systematically evaluating read-across prediction and performance using a local validity approach characterized by chemical structure and bioactivity information. Regul Toxicol Pharmacol 79:12-24

294. CompTox Dashboard. https://comptox.epa.gov/dashboard. Accessed 3 Aug 2018

295. Baker N, Knudsen T, Williams A (2017) Abstract Sifter: a comprehensive front-end system to PubMed. F100Res. https://doi.org/10.12688/f1000 research. 12865.1

296. Gallampois CMJ, Schymanski EL, Krauss M, Ulrich N, Bataineh M, Brack W (2015) Multicriteria approach to select polyaromatic river mutagen candidates. Environ Sci Technol 49:2959-2968

297. Ruttkies C, Schymanski EL, Wolf S, Hollender J, Neumann S (2016) MetFrag relaunched: incorporating strategies beyond in silico fragmentation. J Cheminform. https://doi.org/10.1186/s13321-016-0115-9

298. MetFrag. https://msbi.ipb-halle.de/MetFragBeta/. Accessed 3 Aug 2018

299. GNPS. The future of natural products research and mass spectrometry. https://gnps.ucsd.edu/. Accessed 3 Aug 2018

300. Wang M, Carver JJ, Phelan VV, Sanchez LM, Garg N, Peng Y et al (2016) Sharing and community curation of mass spectrometry data with global natural products social molecular networking. Nat Biotechnol 34:828-837

301. Ankley GT, Bennett RS, Erickson RJ, Hoff DJ, Hornung MW, Johnson RD et al (2010) Adverse outcome pathways: a conceptual framework to support ecotoxicology research and risk assessment. Environ Toxicol Chem 29:730-741

302. Watanabe KH, Andersen ME, Basu N, Carvan MJ 3rd, Crofton KM, King KA et al (2011) Defining and modeling known adverse outcome pathways: domoic acid and neuronal signaling as a case study. Environ Toxicol Chem 30:9-21

303. Aopwiki. https://aopwiki.org. Accessed 3 Aug 2018

304. Sachana M, Munn S, Bal-Price A (2016) Adverse outcome pathway on chronic binding of antagonist to $\mathrm{N}$-methyl-D-aspartate receptors (NMDARs) during brain development induces impairment of learning and memory abilities. OECD Publishing. https://doi.org/10.1787/5jlsq s5hcrmq-en

305. Sachana M, Munn S, Bal-Price A (2016) Adverse Outcome Pathway on binding of agonists to ionotropic glutamate receptors in adult brain leading to excitotoxicity that mediates neuronal cell death, contributing to learning and memory impairment. OECD Series Adverse Outcome Pathways. https://doi.org/10.1787/5j|r8vqgm630-en 
306. Gong P, Hong H, Perkins EJ (2015) lonotropic GABA receptor antagonism-induced adverse outcome pathways for potential neurotoxicity biomarkers. Biomark Med 9:1225-1239

307. Bal-Price A, Lein PJ, Keil KP, Sethi S, Shafer T, Barenys M et al (2017) Developing and applying the adverse outcome pathway concept for understanding and predicting neurotoxicity. Neurotoxicology 59:240-255

308. Paul Friedman K, Watt ED, Hornung MW, Hedge JM, Judson RS, Crofton KM et al (2016) Tiered high-throughput screening approach to identify thyroperoxidase inhibitors within the toxcast phase I and II chemical libraries. Toxicol Sci 151:160-180

309. LaLone CA, Villeneuve DL, Wu-Smart J, Milsk RY, Sappington K, Garber KV et al (2017) Weight of evidence evaluation of a network of adverse outcome pathways linking activation of the nicotinic acetylcholine receptor in honey bees to colony death. Sci Total Environ 584-585:751-775

310. Russom CL, LaLone CA, Villeneuve DL, Ankley GT (2014) Development of an adverse outcome pathway for acetylcholinesterase inhibition leading to acute mortality. Environ Toxicol Chem 33:2157-2169

311. Fay KA, Villeneuve DL, LaLone CA, Song Y, Tollefsen KE, Ankley GT (2017) Practical approaches to adverse outcome pathway development and weight-of-evidence evaluation as illustrated by ecotoxicological case studies. Environ Toxicol Chem 36:1429-1449

312. Knapen D, Angrish MM, Fortin MC, Katsiadaki I, Leonard M, MargiottaCasaluci L et al (2018) Adverse outcome pathway networks i: development and applications. Environ Toxicol Chem. https://doi.org/10.1002/ etc. 4125

313. LaLone CA, Villeneuve DL, Lyons D (2016) ... highlight: sequence alignment to predict across species susceptibility (SeqAPASS): a web-based tool for addressing the challenges of cross-species extrapolation of .... Toxicological. academic.oup.com. https://academic.oup.com/toxsci/ article-abstract/153/2/228/2578709

314. Li X, Yu J, Li J, Wu Y, Li B (2017) Dopaminergic dysfunction in mammalian dopamine neurons induced by simazine neurotoxicity. Int J Mol Sci. https://doi.org/10.3390/ijms18112404

315. Polinsky RJ (1998) Clinical pharmacology of rivastigmine: a new-generation acetylcholinesterase inhibitor for the treatment of Alzheimer's disease. Clin Ther 20:634-647

316. Küster $E$, Altenburger R (2007) Suborganismic and organismic effects of aldicarb and its metabolite aldicarb-sulfoxide to the zebrafish embryo (Danio rerio). Chemosphere 68:751-760

317. Clotfelter ED, Bell AM, Levering KR (2004) The role of animal behaviour in the study of endocrine-disrupting chemicals. Anim Behav 68:665-676

318. Kirubagaran R, Joy KP (1990) Changes in brain monoamine levels and monoamine oxidase activity in the catfish, Clarias batrachus, during chronic treatments with mercurials. Bull Environ Contam Toxicol 45:88-93

319. Weber DN, Connaughton VP, Dellinger JA, Klemer D, Udvadia A, Carvan MJ 3rd (2008) Selenomethionine reduces visual deficits due to developmental methylmercury exposures. Physiol Behav 93:250-260

320. Huang TL, Obih PO, Jaiswal R, Hartley WR, Thiyagarajah A (1997) Evaluation of liver and brain esterases in the spotted gar fish (Lepisosteus oculatus) as biomarkers of effect in the lower Mississippi River Basin. Bull Environ Contam Toxicol 58:688-695

321. Murphy CA, Rose KA, Alvarez MC, Fuiman LA (2008) Modeling larval fish behavior: scaling the sublethal effects of methylmercury to populationrelevant endpoints. Aquat Toxicol 86:470-484

322. Ivan LN, Schmitt BR, Rose KA, Riley SC, Rose JB and Murphy CA (2018) Evaluation of the thiamine dose-response relationship for lake trout (Salvelinus namaycush) fry using an individual based model. J Great Lakes Res. https://doi.org/10.1016/j.jglr.2018.08.013

323. Mora-Zamorano FX, Klingler R, Basu N, Head J, Murphy CA, Binkowski FP et al (2017) Developmental methylmercury exposure affects swimming behavior and foraging efficiency of yellow perch (Perca flavescens) Larvae. ACS Omega 2:4870-4877

324. Armstrong BM, Mora-Zomorano FX, Carvan MN, McNaught S, Basu N, Head J, Klingler RK, Ivan LN, Murphy CA (2018) Yellow perch recruitment in Lake Michigan: exploring the impacts of methylmercury induced behavioral alterations. CJFAS, New York

325. Alvarez MC, Murphy CA, Rose KA, McCarthy ID, Fuiman LA (2006) Maternal body burdens of methylmercury impair survival skills of offspring in Atlantic croaker (Micropogonias undulatus). Aquat Toxicol 80:329-337

326. Mora-Zamorano FX, Klingler R, DeBofsky A, Waltz M, Larson J, Anderson D, Binkowski F, Goetz F, Basu N, Head J, Tonellato P, Murphy CA, Carvan MJ (2018) Gene expression alteration associated with early embryonic methylmercury exposure in zebrafish (Danio rerio) and yellow perch (Perca flavescens). Environ Sci Technol 195:301-311

327. Murphy CA (2006) Modeling the effects of endocrine disrupting chemicals on Atlantic croaker: understanding biomarkers and predicting population responses. http://digitalcommons.lsu.edu/cgi/viewconten t.cgi?article $=1448 \&$ context $=$ gradschool_dissertations

328. Celander MC, Goldstone JV, Denslow ND, Iguchi T, Kille P, Meyerhoff RD et al (2011) Species extrapolation for the 21st century. Environ Toxicol Chem 30:52-63

329. Krewski D, Acosta D Jr, Andersen M, Anderson H, Bailar JC III, Boekelheide $\mathrm{K}$ et al (2010) Toxicity testing in the 21st century: a vision and a strategy. J Toxicol Environ Health B Crit Rev 13:51-138

330. Murphy CA, Garcia-Reyero N, Carvan MJ, Jones, MJ (2015) Development of an adverse outcome pathway for neurodevelopment in larval fish to predict effects of contaminants on survival and growth across multiple ecologically relevant taxa. EPA STAR Grant R835798

331. Hass U (2006) The need for developmental neurotoxicity studies in risk assessment for developmental toxicity. Reprod Toxicol 22:148-156

332. Peterson EK, Buchwalter DB, Kerby JL, LeFauve MK, Varian-Ramos CW, Swaddle JP (2017) Integrative behavioral ecotoxicology: bringing together fields to establish new insight to behavioral ecology, toxicology, and conservation. Curr Zool 63:185-194

333. OECD. Users' Handbook supplement to the Guidance Document for developing and assessing Adverse Outcome Pathways. OECD Series on Adverse Outcome Pathways 2018. https://doi.org/10.1787/5jlv1m9d1g 32-en

334. Villeneuve DL, Angrish MM, Fortin MC, Katsiadaki I, Leonard M, Margiotta-Casaluci L et al (2018) Adverse outcome pathway networks II: network analytics. Environ Toxicol Chem. https://doi.org/10.1002/ etc. 4124 